"Contemporaneous and asymmetric volume-return relationship: cross-product evidence from an emerging market"

AUTHORS Jung-Chu Lin

Jung-Chu Lin (2016). Contemporaneous and asymmetric volume-return

ARTICLE INFO relationship: cross-product evidence from an emerging market. Investment Management and Financial Innovations, 13(1), 92-111. doi:10.21511/imfi.13(1).2016.09

DOI http://dx.doi.org/10.21511/imfi.13(1).2016.09

RELEASED ON Friday, 04 March 2016

JOURNAL "Investment Management and Financial Innovations"

FOUNDER

LLC "Consulting Publishing Company "Business Perspectives"

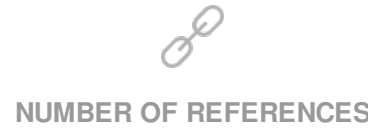

0

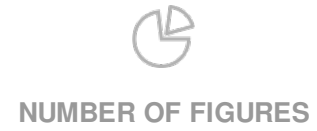

0

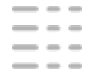

NUMBER OF TABLES

0

(C) The author(s) 2022. This publication is an open access article. 
Jung-Chu Lin (Taiwan)

\title{
Contemporaneous and asymmetric volume-return relationship: cross-product evidence from an emerging market
}

\begin{abstract}
This paper demonstrates that both Taiwan's exchange-traded funds (ETFs) and equities exhibit an asymmetric volumereturn relationship in which the ETF display a mixed, negative or positive, asymmetry and the equity exhibits primarily a positive asymmetry. The positive asymmetry in equities and its decline with the progressive elimination of the shortsale restriction on equities support the costly short-sale hypothesis, which considers a costly short-sale restriction or asymmetric transaction costs on long and short trading to be the source of the asymmetry. The part of a less positive asymmetry in ETFs also consists with what the costly short-sale hypothesis predicts. The later information models that consider asymmetrically-informed traders or the heterogeneity of traders to be the source of the asymmetry explain the negative asymmetry in ETFs and the upward trend in the magnitude of volume-return correlation with the grow of volume quantiles. An important conclusion is that not a single hypothesis can be a universal explanation for the asymmetric volume-return relationship. Which hypothesis may explain the volume-return asymmetry depends largely on whether the short-sale restriction is present.
\end{abstract}

Keywords: exchange-traded fund, asymmetric volume-return relationship, costly short-sale hypothesis, information model, dissemination of information, heterogeneity of traders, quantile regression.

JEL Classification: G12, G14, G18.

\section{Introduction}

Taiwan's exchange-traded funds (ETFs) trade differently from equities primarily in transaction taxes and in their applicability to short-sale restriction. Such reality provides an opportunity to investigate how trade rules or requirements in a same exchange environment affect the volumereturn relationship. While empirical research is used to studying only one class of financial product in a market at a time, this paper simultaneously examines the volume-return relationship in Taiwan's ETF and equity markets and contributes to three aspects: (1) outlining the volume-return relationship for both the ETF and equity in a vital emerging market; (2) retesting the various hypotheses for volume-return relationship; (3) providing valuable evidence for Taiwan's financial market whose regulator and participants are currently considering and arguing the necessary reform for enhancing this market's momentum.

A Wall Street adage goes that "volume is relatively heavy in bull markets and light in bear markets," which indicates a so-called asymmetric relationship between volume and signed returns (price changes per se). Such asymmetric volume-signed return relationship is often observed in equity markets where the volume on a price rise is larger than that on a price decline. In fact, numerous empirical studies on equity markets find an asymmetric trade volume-signed return relationship which is demonstrated, implicitly or explicitly, by a positive correlation between volume and signed returns

(C) Jung-Chu Lin, 2016.

Jung-Chu Lin, Associate Professor, Department of Banking and Finance, Takming University of Science and Technology, Taiwan.
(Chuang and Kuan, 2005; Epps, 1977; Hanna, 1978; Harris and Gurel, 1986; Morgan, 1976; Richardson et al., 1986; Rogalski, 1978; Ying, 1966).

The "costly short-sale hypothesis" is proposed to explain this asymmetric effect in equity markets since the presence of a short-sale restriction makes a short position in this market more costly than a long position (Jennings et al., 1981) and hence results in smaller volumes on price declines and in decreases in the variance of intertemporal shifts in transaction supply relative to that of transaction demand (Karpoff, 1988). These in turn result in a positive correlation between volume and signed returns which indicates an asymmetric volume-signed return relationship.

If the "costly short-sale hypothesis" holds true, the above asymmetric volume-return relationship should not be found in futures markets where the costs of assuming long and short positions are identical. In fact, early studies on various futures markets document no positive correlation between volume and signed returns (Karpoff, 1988; Kocagil and Schachmurove, 1998; McCarthy and Najand, 1993). They find instead a positive correlation between volume and "absolute" returns, which does not necessarily indicate a positive correlation between volume and signed returns. However, recent studies, e.g. Moosa et al. (2003), Puri and Philippatos (2008), and $\mathrm{He}$ et al. (2014), find exceptions to this conventional non-asymmetric result from futures markets. Puri and Philippatos (2008) demonstrate that interest rate and currency futures on the London International Financial Futures and Options Exchange (LIFFE) exhibit an asymmetric volume-signed return relationship characterized by significantly larger volume 
associated with negative returns than with nonnegative returns. He et al. (2014) find a positive correlation between volume and signed returns, i.e. an asymmetric volume-signed return relationship characterized by significantly larger volume associated with non-negative returns than with negative returns, in China's agricultural commodity futures markets. Even in equity markets, several studies (Brennan et al., 1998; Chordia et al., 2001; Wood et al., 1985) provide evidence of a negative asymmetric volume-return relationship in which volume on a price decline is larger than on a price rise.

Compared with the "costly short-sale hypothesis" in explaining the asymmetric volume-return relationship, information models that consider "the dissemination of information" or "the heterogeneity of traders" appear to provide a more rigorous explanation for some of the observed results. In the early literature, two main hypotheses regarding the dissemination of information are the mixture of distribution hypothesis (MDH) (Clark, 1973; Epps and Epps, 1976; Harris, 1986; Tauchen and Pitts, 1983) and the sequential information model (SIM) (Copeland, 1976; Jennings et al., 1981; Jennings and Barry, 1983; Smirlock and Starks, 1985). The MDH assumes that new information arrives to all market participants simultaneously and hence implies an instantaneous adjustment to final equilibrium and a significant contemporaneous correlation between volume and signed returns. The SIM, on the other hand, postulates that information arrives to traders sequentially and hence implies a gradual adjustment to full-information equilibrium and a positive volume-absolute return correlation. Although the $\mathrm{MDH}$ tries to accentuate the leading role of returns to volume, this hypothesis hardly indicates any intertemporal relationship between volume and returns, which is nevertheless implied in the SIM.

In the later literature, information models that incorporate heterogeneous traders with asymmetric information, i.e. informed and less informed or uninformed traders, have gained importance in explaining some of the observed volume-return regularities. In the dispersion-of-beliefs model outlined by Daigler and Wiley (1999), Harris and Raviv (1993), and Shalen (1993), uninformed or less informed traders who cannot distinguish a random liquidity demand from the fundamental changes in demand and supply contribute to a greater dispersion of beliefs and the subsequent excess volume and volatility. This model believes that the dispersion of beliefs has a positive link with both price variability and trade volume and hence drives the subsequent positive volume-volatility relationship. Since the uninformed traders do not have linear unbiased expectation conditioned on the incoming information, price declines add to greater dispersion of beliefs and relatively larger abnormal volume on negative returns bringing out a negative asymmetric volume-signed return relationship. Likewise, in the dispersion-of-information model by Blume et al. (1994), the two groups, i.e. informed and uninformed traders, receive a signal from a common source, yet their dispersions of information are different in the sense that the traders in each group have a different precision or "quality" for the signal. Since under this information structure traders in group 2, the uninformed traders, do not know the signal precision, they look for additional information contained in volume which leads to two important propositions demonstrated by Blume et al. (1994): (1) both volume and price convey signals to the market where volume conveys the signal quality and price conveys the signal quantity, resulting in a volume-return relationship which is determined by the quantity and quality of information available to traders; (2) under certain conditions of the signal precision, volume behaves as a convex function of price and hence the volume-return behavior is asymmetric. In general, these later information models provide justification not only for a contemporaneous relationship between volume and returns but also for the asymmetry present to this relationship.

Over the past few years, ETFs have grown in size to reach over US\$2 trillion in total assets, a reflection of their acceptance as an investment option in addition to futures or options and as part of a broader asset allocation strategy. In the Asia-Pacific region, ETFs are gaining ground as more providers launch new products and investors begin to learn the merits of investing in them. At the rate it is growing, the Asian ETF market may soon overtake Europe. However, while equity and futures markets in developed and emerging nations have been intensively investigated, in the research on volumereturn relationship few can be found for ETF markets in the Asia-Pacific region. Therefore, this study chooses Taiwan, one of the most prominent emerging economies, to examine the volume-return relationship of its ETF market while the volumereturn relationship of its equity market is also examined as a comparison. These comparative examinations not only test various hypotheses for the volume-return relationship further but also provide insight into the information structure and dissemination of ETF and equity markets, aiding in a better performance of investment management and in a valuable reference for market reforms.

In Taiwan, short sales of ETFs differ from those of general equities in two ways: (1) short selling on ETFs is levied by a lower transaction tax of $0.1 \%$ 
than that of $0.3 \%$ levied on general shares; (2) while those general shares are constrained by the shortsale restriction, which requires short sales to take place at the price no lower than the previous day's closing price, ETFs are exempted from this local uptick rule. However, the short selling of ETFs is still regulated by the general short-sale margin requirement, which is $90 \%$ of the trade value compared to a lower margin requirement $40 \%$ for the margin buying. Therefore, the costly short-sale hypothesis would first of all predict an obviously positive asymmetric volume-return relationship in Taiwan's equity market and a less positive asymmetric volume-return relationship in the ETF market. Secondly, since the short-sale uptick rule levied on the equity market is eliminated progressively since May 16, 2005 to an entire elimination on September 23, 2013, the costly shortsale hypothesis would predict a diminish in this positive asymmetry in equity's volume-return relationship with the gradual elimination of the short-sale restriction. To verify this prediction, I partition the equity data period to three sub periods which are pre-eliminated (June 30, 2003 to May 13, 2005 and September 22, 2008 to December 31, 2008), partly-eliminated (May 16, 2005 to September 19, 2008 and January 5, 2009 to September 18, 2013), and entirely-eliminated (September 23, 2013 to December 31, 2014) periods to observe any change in equity's volume-return relationship. Moreover, in terms of the viewpoints of the later information models, i.e. the dispersionof-beliefs or the dispersion-of-information models, as Taiwan's ETFs are not constrained by the shortsale restriction and are not so costly when short selling compared with the equities, a negative asymmetry would possibly be observed in their volume-return relationship since these models predict that price declines add to greater dispersion of beliefs and larger abnormal volume on negative returns when there is no short-sale restriction. Finally, both the MDH and the later information models would predict a significant contemporaneous correlation between volume and signed returns for both ETF and equity markets. In general, the above predictions are verified by a comparative investigation into the ETF and equity's volumereturn relationships.

The empirical results reveal a highly significant contemporaneous volume-signed return relationship in both the ETF and equity markets, indicating that neither the MDH nor the later information models can be rejected. The results also show that the significant contemporaneous volume-signed return relationships in the equity market exhibit a positive asymmetry and this asymmetry declines with the elimination of the short-sale restriction, indicating that the costly short-sale hypothesis cannot be rejected either. The prediction of negative asymmetries in ETF's volume-return correlation is also confirmed, indicating that the later information models can explain some of the observed volumereturn regularities. Moreover, the magnitude of the correlations of volume associated with either direction of returns is stronger for ETFs than for equities and the magnitude of these correlations for equities grows with the gradual elimination of the short-sale uptick rule, indicating the influence of the short-sale restriction. Nevertheless, since in the entirely-eliminated period, the magnitude of volume-return correlations associated with both directions of returns for equities is still weaker than that for ETFs, some factors like transaction costs or the product characteristic per se, other than shortsale restrictions, should affect the volume-return relationship. Therefore, the recent initiatives concerning market reforms, like the reduction of transaction costs, are critical to the enhancement of the market momentum.

The remainder of this paper is organized as follows. Section 1 presents the model specifications and their estimation. Section 2 describes the data and summary statistics. Section 3 provides the empirical results and their discussion. Final section presents the concluding remarks.

\section{Model specification and estimation}

Contemporaneous correlation between volume and signed returns provides a measure to evaluate the asymmetric relationship in financial markets. Conventional practice estimates this correlation by directly regressing volume against signed returns to observe volume-return connection and its asymmetry. Comprehensively considering the models specified in Puri and Philippatos (2008) and He et al. (2014), I construct a model as equation (1) to provide direct measures for the contemporaneous correlations of volume with both the negative and non-negative returns. By introducing a dummy variable, $D_{t}$, in equation (1), a measure of asymmetric volume response to signed returns is also obtained.

$V_{t}=c+a \times V_{t-1}+b \times S R_{t}+\gamma \times D_{t} \times S R_{t}+\varepsilon_{t}$.

$V_{t}$ is the trade volume in the trading day $t$. In this study, the natural logarithms of share and dollar turnovers, called log share volume and log dollar volume respectively, are used as the trade volume. $S R_{t}$, calculated by $\log$ price change $100 \% \times \log \left(P_{t} / P_{t-1}\right)$, is the signed return over the trading day $t$ where $P_{t}$ is the price at time $t$ and so forth. $D_{t}$ is a dummy variable for the trading day $t$ that equals one for negative returns and zero for non-negative returns. 
Intercept $c$, coefficients $a, b$, and $\gamma$ are parameters of the regression. This structure allows us to investigate the connections between volume and either direction of returns as measured by the slope estimates $b$ for the non-negative and $(b+\gamma)$ for the negative returns, respectively. If both the coefficients, $b$ and $\gamma$, are significant, the volumereturn relationship is asymmetric.

The theoretical foundation of the specification in equation (1) is consistent with the MDH and the later information models. In the $\mathrm{MDH}$, an exogenous common mixing variable moves both volume and returns, leading to contemporaneous volume-return correlations. In the dispersion-of beliefs model, uninformed traders react not only to the price changes but also to the changes in volume as if these changes reflect information, leading to a greater dispersion of beliefs and the subsequent contemporaneous volume-return correlations. Similarly, in the dispersion-of-information model, both volume and the contemporaneous price convey information to the market and thus they must be correlated. All these models provide justification for a contemporaneous relationship between volume and returns, whereas the later information models further provide alternative explanation for the asymmetric feature observed in the volume-return relationship.

I use the ordinary least squares (OLS) method, the general autoregressive conditional heteroskedasticity (GARCH) model, and the quantile regression method to estimate equation (1). The OLS method estimates parameters by minimizing the sum of squared errors and then obtains results that are approximations to the mean function of the conditional distribution of the dependent variable. Since autocorrelation, heteroskedasticity, and volatility clustering are commonly present in financial time-series data, I use GARCH $(1,1)$ model to remedy these problems and hence set the conditional error $\left(\varepsilon_{t}\right)$ distribution and the conditional variance $\left(h_{t}\right)$ equation of the errors as equation (2) and (3), respectively.

$$
\begin{aligned}
& \varepsilon_{t} \sim N\left(0, h_{t}\right), \\
& h_{t}=\alpha_{0}+\alpha_{1} \times \varepsilon_{t-1}^{2}+\beta_{1} \times h_{t-1} .
\end{aligned}
$$

Moreover, since the conventional OLS method only addresses the conditional mean or the central effects of the covariates, i.e. the "average" behavior of a distribution, this method is incapable of characterizing the entire conditional distribution of the outcome variable. Consequently, I use the quantile regression method, proposed by Koenker and Bassett (1978), to assess the covariate effects at various quantiles of the outcome so as to quantify the entire conditional distribution of the outcome variable. In particular, this method can model the lower to higher quantiles of the outcome to give an overall assessment of covariate effects across various quantiles. For instance, in this study, each volume series, i.e. the outcome variable in equation (1), is specified by 21 quantiles, which are 0.01 , $0.05,0.10,0.15, \ldots, 0.85,0.90,0.95,0.99$, and hence 21 covariate effects (the volume-return correlations) for the respective 21 quantiles can be evaluated and compared to exhibit a clearer picture of the volumereturn behavior. In addition, since it does not require strong distribution assumptions, the quantile regression offers a distributionally robust method for relationship modeling. Performing the quantile regression, I use the bootstrapping technique to estimate coefficient covariance and standard errors, which, according to Rogers (1992), is less sensitive to heteroskedasticity.

\section{Data and summary statistics}

The first ETF in Taiwan's market, launched on June 30, 2003, is the Yuanta/P-shares Taiwan Top 50 ETF (Taiwan 50 ETF, code: ETF_0050). Of the 14 ETFs investing in domestic equities listed on the Taiwan Stock Exchange Corporation (TWSE), Taiwan 50 ETF not only has the longest trade history but also is traded sustainably with the highest turnover (see Figure 1 using 2014 data as an example). Its yearly dollar turnover has grown from 79 NT\$ billion to a record high of 284 NT\$ billion in 2011 and sustainably accounts for more than $85 \%$ of the entire ETF market dollar turnover (see Figure 2). Therefore, I use data on the Taiwan 50 ETF share turnover, dollar turnover, and sign returns to explore the volume-return relationship in Taiwan's ETF market.

For a comparison base, I also assess the volumereturn relationship of Taiwan's equity market by using the transaction data on the Taiwan Stock Exchange Capitalization Weighted Stock Index (TAIEX). The data period for both the ETF and equity index spans from June 30, 2003 to June 30, 2015, amounting to 2981 observations on a daily basis. Moreover, while the short selling of Taiwan's ETFs is exempted from the uptick rule, the shortsale uptick rule levied on the equity market is present but eliminated progressively over the data period. Consequently, I partition the TAIEX data period to three sub periods: the pre-eliminated period, the partly-eliminated period, and the entirely-eliminated period to examine any change in TAIEX's volume-return connection with the phased elimination of the short-sale restriction. The daily volume and return data are obtained from the Taiwan Economic Journal (TEJ) database. 


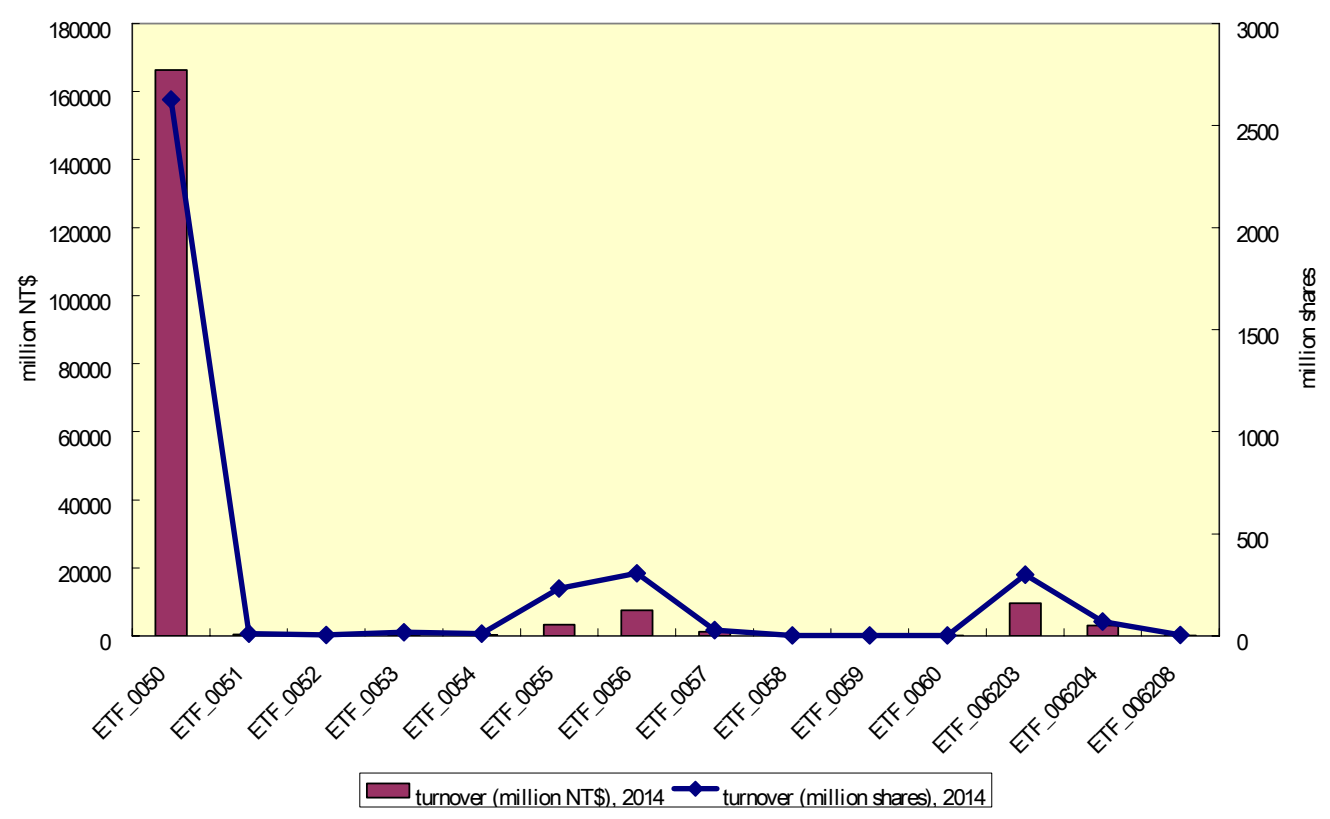

Fig. 1. 2014 turnovers of the 14 ETFs on TWSE

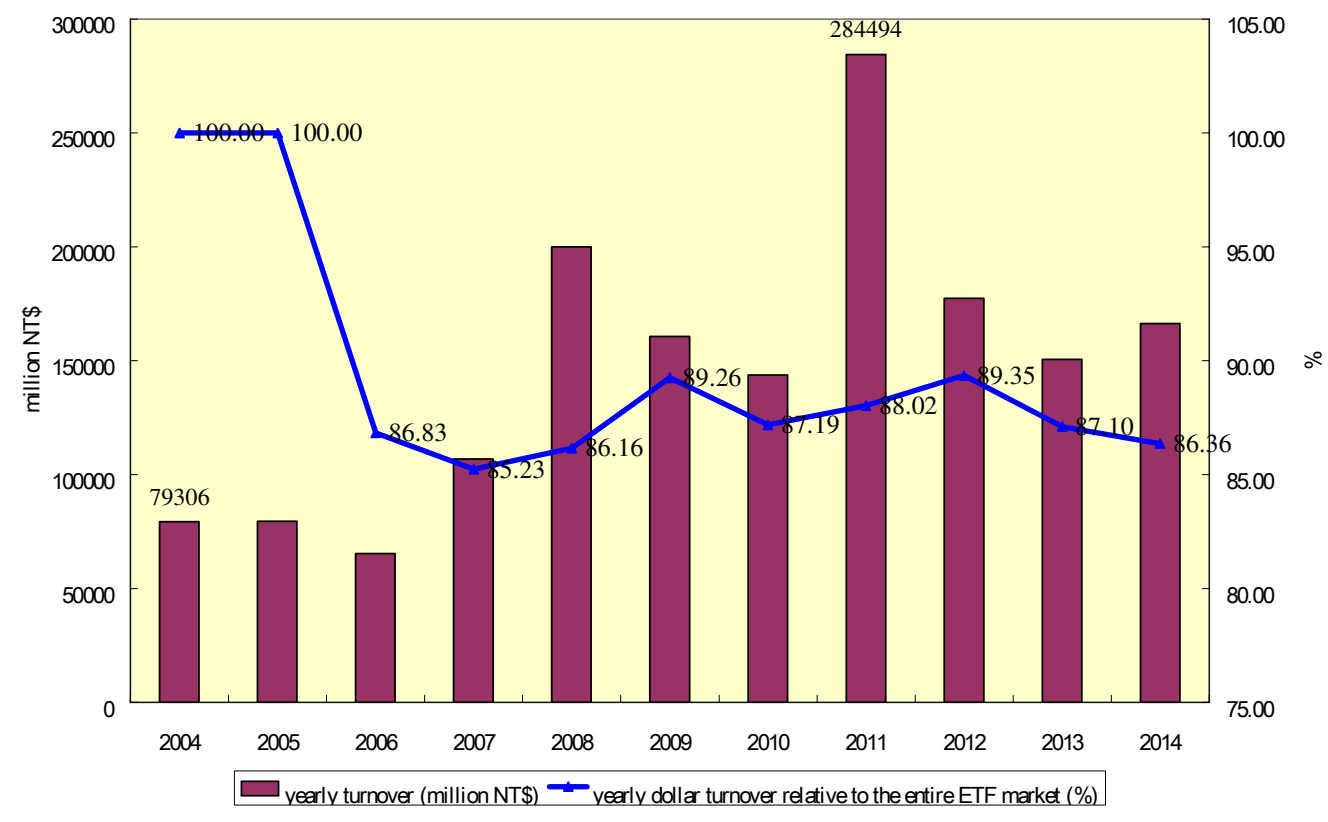

Fig. 2. Yearly turnovers of the Taiwan 50 ETF, absolute numbers and relative to the entire ETF market, 2004 to 2014

Table 1 presents the descriptive statistics for the full sample of the daily volume and return data for both the ETF and TAIEX. The descriptive statistics for the three sub periods of the equity index are presented in Table 2 to observe the differences among them. The descriptive statistics show that the probability density functions of volume for the ETF are left skewed (negative skewed), and those for the equity index are from right skewed (positive skewed) in the pre- and partly-eliminated periods to left skewed in the entirely-eliminated period. As for the return series, the density functions for both the
ETF and TAIEX are left skewed and leptokurtic, similar to those found in the past literature. The leptokurtosis of the return series indicates that the return data points are clustered around the mean, resulting in a high peak and fat tails of the distribution shape. Augmented Dickey-Fuller (ADF) test and Phillips-Perron (PP) test are used to perform the unit root test for the data series. The ADF and PP test results in Tables 1 and 2 suggest that the null hypothesis can be rejected at any level of significance for all the volume and return series, thereby indicating that all the series are stationary. 
Table 1. Descriptive statistics for the share volume, dollar volume, and returns series of the ETF and the equity index: full sample, June 30, 2003 to June 30, 2015

\begin{tabular}{|c|c|c|c|c|c|c|}
\hline \multirow{2}{*}{ Statistics } & \multicolumn{3}{|c|}{ Taiwan 50 ETF } & \multirow[b]{2}{*}{ Share volume } & \multirow{2}{*}{$\begin{array}{c}\text { TAIEX } \\
\text { Dollar volume } \\
\end{array}$} & \multirow[b]{2}{*}{ Return (\%) } \\
\hline & Share volume & Dollar volume & Return (\%) & & & \\
\hline Observations & 2981 & 2981 & 2981 & 2981 & 2981 & 2981 \\
\hline Mean & 9.029 & 13.002 & 0.034 & 15.194 & 18.372 & 0.022 \\
\hline Median & 9.051 & 13.042 & 0.044 & 15.190 & 18.364 & 0.069 \\
\hline Maximum & 11.833 & 15.777 & 6.765 & 16.269 & 19.590 & 6.525 \\
\hline Minimum & 6.324 & 10.357 & -7.257 & 14.150 & 16.987 & -6.912 \\
\hline Std. dev. & 0.746 & 0.755 & 1.336 & 0.306 & 0.339 & 1.244 \\
\hline Skewness & -0.193 & -0.257 & -0.142 & 0.157 & 0.003 & -0.408 \\
\hline Kurtosis & 2.988 & 3.026 & 8.169 & 2.944 & 3.294 & 6.657 \\
\hline \multirow{2}{*}{ ADF unit root test } & -8.290 & -9.011 & -54.954 & -6.145 & -5.806 & -51.529 \\
\hline & $(0.000)^{\star \star \star}$ & $(0.000)^{\star \star \star}$ & $(0.000)^{\star \star \star}$ & $(0.000)^{\star \star \star}$ & $(0.000)^{\star \star \star}$ & $(0.000)^{* \star \star}$ \\
\hline \multirow{2}{*}{ PP unit root test } & -44.165 & -44.516 & -55.104 & -20.031 & -21.113 & -51.490 \\
\hline & $(0.000)^{\star \star \star}$ & $(0.000)^{\star \star \star}$ & $(0.000)^{\star \star \star}$ & $(0.000)^{\star \star \star}$ & $(0.000)^{\star \star \star}$ & $(0.000)^{\star \star \star}$ \\
\hline
\end{tabular}

Notes: Figures of share and dollar volumes are log values. Returns are calculated by log price change $100 \% \times \log \left(P_{t} / P_{t-1}\right)$. Those in parentheses are $p$-values for the unit root test statistics. *** indicates significance at the $1 \%$ level.

Table 2. Descriptive statistics for the share volume, dollar volume, and returns series of the equity index

TAIEX: three sub-periods

\begin{tabular}{|c|c|c|c|c|c|c|c|c|c|}
\hline \multirow[b]{2}{*}{ Statistics } & \multicolumn{3}{|c|}{ Pre-eliminated } & \multicolumn{3}{|c|}{ Partly-eliminated } & \multicolumn{3}{|c|}{ Entirely-eliminated } \\
\hline & $\begin{array}{l}\text { Share } \\
\text { volume }\end{array}$ & $\begin{array}{l}\text { Dollar } \\
\text { volume }\end{array}$ & Return (\%) & $\begin{array}{l}\text { Share } \\
\text { volume }\end{array}$ & $\begin{array}{l}\text { Dollar } \\
\text { volume }\end{array}$ & Return (\%) & $\begin{array}{l}\text { Share } \\
\text { volume }\end{array}$ & $\begin{array}{l}\text { Dollar } \\
\text { volume }\end{array}$ & Return (\%) \\
\hline Observations & 538 & 538 & 538 & 2008 & 2008 & 2008 & 435 & 435 & 435 \\
\hline Mean & 15.154 & 18.191 & -0.011 & 15.165 & 18.432 & 0.029 & 15.382 & 18.317 & 0.029 \\
\hline Median & 15.101 & 18.153 & 0.029 & 15.155 & 18.432 & 0.080 & 15.392 & 18.323 & 0.062 \\
\hline Maximum & 16.269 & 19.359 & 6.099 & 16.165 & 19.590 & 6.525 & 15.883 & 18.943 & 1.901 \\
\hline Minimum & 14.150 & 16.987 & -6.912 & 14.454 & 17.334 & -6.735 & 14.926 & 17.488 & -2.886 \\
\hline Std. dev. & 0.387 & 0.412 & 1.517 & 0.287 & 0.324 & 1.255 & 0.181 & 0.179 & 0.700 \\
\hline Skewness & 0.421 & 0.264 & -0.342 & 0.302 & 0.103 & -0.397 & -0.119 & -0.012 & -0.518 \\
\hline Kurtosis & 2.680 & 2.929 & 6.305 & 3.058 & 2.905 & 5.840 & 2.806 & 4.098 & 4.330 \\
\hline \multirow{2}{*}{ ADF unit root test } & -5.291 & -5.639 & -20.991 & -5.654 & -4.821 & -42.812 & -6.013 & -7.884 & -20.453 \\
\hline & $(0.000)^{\star \star \star}$ & $(0.000)^{+*+*}$ & $(0.000)^{\star \star \star}$ & $(0.000)^{\star \star *}$ & $(0.000)^{\star * \star}$ & $(0.000)^{\star \star \star}$ & $(0.000)^{\star \star \star}$ & $(0.000)^{\star \star \star}$ & $(0.000)^{\star \star \star}$ \\
\hline \multirow{2}{*}{ PP unit root test } & -9.470 & -10.290 & -20.906 & -15.995 & -16.377 & -42.774 & -9.984 & -10.935 & -20.622 \\
\hline & $(0.000)^{\star \star \star}$ & $(0.000)^{* \star *}$ & $(0.000)^{\star * *}$ & $(0.000)^{\star \star \star}$ & $(0.000)^{\star * *}$ & $(0.000)^{\star * *}$ & $(0.000)^{\star \star *}$ & $(0.000)^{\star \star \star}$ & $(0.000)^{\star \star \star}$ \\
\hline
\end{tabular}

Notes: Figures of share and dollar volumes are log values. Returns are calculated by log price change $100 \% \times \log \left(P_{t} / P_{t-1}\right)$. Those in parentheses are $p$-values for the unit root test statistics. *** indicates significance at the $1 \%$ level.

\section{Empirical results and discussion}

Three methods are used to estimate equation (1). Each method has eight estimation results since four data periods need to be estimated and two volume series, share and dollar volume, need to be considered in each period. Tables 3 and 4 present the OLS and GARCH estimates, respectively. Table 5 presents the quantile regression results for Taiwan $50 \mathrm{ETF}$ in the full-sample period. The quantile regression results for TAIEX in the three sub periods (pre-eliminated, partly-eliminated, and entirely-eliminated data periods) are presented in Tables 6 to 8, respectively. Regarding the volumereturn relationship, the ETF and the three sub-period TAIEX results are compared to find the difference between them or the change in TAIEX itself induced by the elimination of the short-sale restriction.
Estimates from equation (1) provide measures not only for the autocorrelation of volume series but also for the correlations between volume and either direction of returns. Slope $a$, reported in each of Tables 3 to 8 , reflects the autocorrelation degree of volume series. To compare this autocorrelation across different volume quantiles and across the ETF and TAIEX's three sub periods, Figure 3 graphically presents the slope $a$ estimates for the four data periods by the quantile regression method. Slope $b$ is observed for the correlation between volume and non-negative returns, and slopes $b+\gamma$ are used for the correlation between volume and negative returns. These correlations, $b$ and $b+\gamma$, are also reported in each of Tables 3 to 8 and graphically presented in Figures 4 and 5. The two figures plot the correlation estimates across the 21 volume quantiles for the ETF and TAIEX, 
respectively. Normally, the slope coefficient associated with non-negative returns, $b$, should be positive and the coefficients associated with negative returns, $b+\gamma$, should be negative. However, negative $b$ and positive $b+\gamma$ can possibly be obtained since an autoregressive term $V_{t-1}$ is included in equation (1).

Extensive studies on equity markets identify a positive contemporaneous correlation between volume and signed returns, implying an asymmetry in the volume-signed return relationship (Karpoff, 1987). In this study, the significance of the two slope estimates, $b$ and $\gamma$, is synthetically observed to preliminarily confirm the presence of the asymmetry in the volume-signed return sample. The sum of the two correlation measures, i.e. $b+(b+\gamma)$, is calculated to evaluate the asymmetric effect, which is also reported in each of Tables 3 to 8 , to observe both the asymmetric direction and magnitude of the volume-signed return relationship. Such asymmetric effects across the 21 volume quantiles for the ETF and TAIEX are compiled and graphically presented in Figures 4 and 5, respectively. A positive $b+(b+\gamma)$ indicates a positive asymmetric relationship between volume and signed returns, as the old adage describes: "volume is much heavier in bull markets than in bear markets". On the contrary, a negative $b+(b+\gamma)$ indicates a negative asymmetric relationship between volume and signed returns where the volume on negative returns is greater than that on non-negative returns.

3.1. Autocorrelation of volume series. Coefficient $a$ measures the autocorrelation degree of volume series. All the estimates of $a$ from the three estimation methods are statistically significant at $1 \%$, indicating a strong autocorrelation in each volume series for both the ETF and the equity index (TAIEX). Several inferences can be drawn from the estimates. Firstly, the autocorrelations for TAIEX volume series are mostly stronger than those for the ETF volume series (see Tables 3 to 8 and Figure 3). Secondly, the quantile regression results for all the ETF, TAIEX in the pre-eliminated period and TAIEX's dollar volume in the entirely-eliminated period show that the autocorrelation degree diminishes with the rise of volume quantile, e.g. the autocorrelation of dollar volume for the ETF decreases from 0.752 at quantile 0.01 to 0.462 at quantile 0.99 . The results imply that when volume is at a higher level, it is less affected by the volume of the former period. Thirdly, with the elimination of the short-sale restriction, the autocorrelation of TAIEX volume series averagely weakens (see Tables 3, 4, 6, 7, and 8 and Figure 3). For instance, the autocorrelation of TAIEX's dollar volume, estimated from the GARCH method, declines from 0.841 to a low of 0.674. Overall, the inferences above indicate that the trading volume for both the ETF and TAIEX is highly correlated to its formerperiod volume, yet this correlation declines as the volume level climbs and with the elimination of the short-sale restriction.

3.2. Contemporaneous volume-signed return relationship. Coefficient $b$ is used to measure the contemporaneous correlation between volume and non-negative returns, and coefficients $b+\gamma$ are used to measure the correlation between volume and negative returns. All the estimates of $b$ and $\gamma$ for the ETF are statistically significant at $1 \%$, indicating a strong contemporaneous relationship between ETF volume and signed returns (see Tables 3 to 5). In the case of TAIEX, all the estimates of $b$ and $\gamma$ in the three sub periods by OLS and GARCH estimation methods are also statistically significant at $1 \%$, indicating a strong contemporaneous relationship between TAIEX volume and signed returns (see Tables 3 and 4). As for the TAIEX results from the quantile regression method, nearly all the estimates of $b$ and $\gamma$ for all the three sub periods across various volume quantiles are highly significant except some estimates for the lower or higher quantiles in pre- and entirely-eliminated sub periods (see Tables 6 to 8). Overall, the results above indicate that the trading volume for both the ETF and TAIEX is highly correlated to either direction of returns, implying that the MDH cannot be rejected. Since the rationale of the later information models also infers a contemporaneous volume-return correlation, these models cannot be rejected either.

The slope coefficients associated with negative returns, $b+\gamma$, are commonly negative for all the ETF results. In the case of TAIEX, the estimates $b+\gamma$ are basically negative with a few exceptions. These exceptions include the result from the GARCH method for the case of dollar volume on negative returns in the pre-eliminated period and some results from the quantile regression method for both volumes on negative returns at the lower quantiles 0.01 to 0.35 in the pre-eliminated period. The exceptions at the lower volume quantiles may suggest that the short-sale restriction restrain the volume at a lower level from reacting to the negative information, or that the uninformed traders, who do not know the signal precision and are conditioned on the additional information in lowerlevel volume, decide not to react too actively to a signal, an implication drawn by the later information models. The evidence that the correlations between volumes and negative returns become particularly strong at the highest volume quantile 0.99 in the pre-eliminated period cooperates with the latter suggestion mentioned above and hence lends support to the later information models. The models 
assert that the uninformed traders look for additional information in volume when they make trade decisions and that a price decline adds to greater dispersion of beliefs or the underlying information signal and thus results in larger abnormal volume on return changes. The distributions of ETF correlations of volume with either direction of returns across quantiles provide another support for the above inference.

Moreover, the magnitude of $b+\gamma$ is greater for the ETF than for TAIEX and the magnitude of this value for TAIEX grows with the gradual elimination of the short-sale uptick rule (see Tables 3 to 8 and Figures 4 and 5), indicating the influence of the short-sale restriction on the correlation of volume to negative returns in another way and suggesting that the elimination of the short-sale restriction may link the volume and negative returns closer. The slope coefficient associated with non-negative returns, $b$, is all positive for both the ETF and TAIEX (those which are not positive are not statistically significant and therefore are not considered), yet is stronger for the ETF than for TAIEX. In particular, the coefficient $b$ 's value is greater for the ETF, although this value for TAIEX attains its highest in the entirely-eliminated period, indicating that the elimination of the short-sale restriction magnifies the connection of volume not only to negative returns but also to non-negative returns. The costly short-sale restriction seems to affect the contemporaneous correlations of volume associated with not only negative but also nonnegative returns. However, even in the entirely-eliminated period, the magnitude of volume-return correlations for both directions of returns is still weaker than that for the ETF, indicating that other than short-sale restrictions, some factors like transaction costs or the product characteristic per se may affect the volume-return relationship. Consequently, the recent initiatives concerning market reforms, such as the reduction of transaction costs, are necessary to enhance the market momentum.

3.3. Asymmetry in the volume-signed return relationship. In this study, the asymmetric effect for the volume-signed return relationship is firstly confirmed by the significance of coefficient $\gamma$. Since the estimates of $\gamma$ are statistically significant for all the ETF and for nearly all the TAIEX results, the presence of asymmetry in volume-signed return relationship for both the ETF and TAIEX is confirmed. The asymmetric measure $b+(b+\gamma)$ is then calculated to ascertain both the direction (negative or positive) and magnitude of the asymmetry. In the case of the ETF, the asymmetric measure $b+(b+\gamma)$ estimated from the OLS and GARCH methods is negative for three of the four results, whereas from the quantile regression method this measure is negative for 22 of the 42 results. Such results show that the negative and positive asymmetries are simultaneously present in the ETF volume-signed return relationship, yet the negative accounts for a slightly higher proportion. Such asymmetric effect for the ETF is different not only from the traditionally observed effect in equity markets but also from the positive asymmetric effect for TAIEX observed in the study described as follows. In general, the part of slightly positive asymmetric volume-return relationship in the ETF market does not contradict the prediction of the costly short-sale hypothesis, indicating that this hypothesis cannot be rejected. Nevertheless, the part of slightly negative asymmetric volume-return relationship in the ETF market does not contradict the prediction of the later information models either and hence lends support to these models as possible explanations for the asymmetric volume-return relationship observed in the ETF market.

In the case of TAIEX, all the asymmetric measure $b+(b+\gamma)$ estimates from OLS and GARCH methods are positive, indicating a primarily positive asymmetric effect as predicted by the costly shortsale hypothesis and as traditionally observed in equity markets. With the elimination of the shortsale uptick rule, the asymmetric value diminishes (e.g. from 0.118 to 0.049 in the GARCH results for dollar volume on returns). As for the quantile regression results, TAIEX's volume-signed return relationship in the pre-eliminated period exhibits a consistently positive asymmetry except the results at quantile 0.99 . The exceptions, i.e. the extremely negative asymmetric volume-signed return relationship at quantile 0.99 for TAIEX in the preeliminated period, corroborate the perspectives of the later information models, which emphasize the role of volume to the uninformed traders and suggest that volume behaves a convex function of price and that price declines add to greater dispersion of beliefs and larger abnormal volume on negative returns (a negative asymmetric volumesigned return relationship). TAIEX's volume-signed return relationship in the partly-eliminated period also exhibits a consistently positive asymmetry except the result for the share volume on returns at quantile 0.01 and 0.05 . As regards the entirelyeliminated period, all the asymmetric measure $b+(b+\gamma)$ estimates are positive. For a clearer comparison, I set the vertical axis scale with identical range, which is from -0.45 to 0.35 , for all the diagrams in Figures 4 and 5. Figure 5 displays that the degree of asymmetry in the pre-eliminated period is greater than the degrees in the other two periods and thus demonstrate once again that with 
the elimination of the short-sale uptick rule, the degree of positive asymmetry diminishes. Moreover, Figures 4 and 5 synthetically show that the degree of asymmetries present in TAIEX is obviously larger than that in the ETF, consisting with the prediction of the costly short-sale hypothesis.

Overall, this study comes to an important conclusion that not a single hypothesis can be a universal explanation for the asymmetric volume-return relationship. Which hypothesis may explain the asymmetrical relationship between volume and signed returns depends on whether the short-sale restriction is present. The costly short-sale hypothesis can explain the volume-return relationship of the market with a short-sale restriction, whereas the information models can explain the volume-return relationships for the markets where the costs and restriction on long and short trading are identical.

Table 3. OLS estimates of volume-signed return correlation

\begin{tabular}{|c|c|c|c|c|c|c|c|}
\hline & $c$ & $a$ & $b$ & y & $b+y$ & $b+(b+\gamma)$ & Adj. $R^{2}$ \\
\hline \multicolumn{8}{|c|}{ Panel A. Taiwan 50 ETF: full-sample period, 2981 observations } \\
\hline \multirow{2}{*}{ Share volume vs. returns } & 3.329 & 0.608 & 0.225 & -0.460 & \multirow{2}{*}{-0.235} & \multirow{2}{*}{-0.010} & \multirow{2}{*}{0.499} \\
\hline & $(28.313)^{\star \star \star}$ & $(46.646)^{\star \star \star}$ & $(18.091)^{\star \star \star}$ & $(-23.251)^{\star \star \star}$ & & & \\
\hline \multirow{2}{*}{ Dollar volume vs. returns } & 4.577 & 0.633 & 0.215 & -0.429 & \multirow{2}{*}{-0.214} & \multirow{2}{*}{0.001} & \multirow{2}{*}{0.497} \\
\hline & $(27.028)^{\star * \star}$ & $(48.623)^{\star * *}$ & $(17.045)^{\star \star \star}$ & $(-21.442)^{\star \star \star}$ & & & \\
\hline \multicolumn{8}{|c|}{ Panel B. TAIEX: pre-eliminated period, 538 observations } \\
\hline \multirow{2}{*}{ Share volume vs. returns } & 2.783 & 0.813 & 0.100 & -0.108 & \multirow{2}{*}{-0.008} & \multirow{2}{*}{0.092} & \multirow{2}{*}{0.708} \\
\hline & $(7.845)^{\star \star *}$ & $(34.763)^{\star * \star}$ & $(9.393)^{\star \star \star}$ & $(-6.587)^{\star \star \star}$ & & & \\
\hline \multirow{2}{*}{ Dollar volume vs. returns } & 3.347 & 0.813 & 0.110 & -0.109 & \multirow{2}{*}{0.001} & \multirow{2}{*}{0.111} & \multirow{2}{*}{0.700} \\
\hline & $(7.725)^{\star \star *}$ & $(34.210)^{\star \star \star}$ & $(9.487)^{\star \star \star}$ & $(-6.139)^{\star \star \star}$ & & & \\
\hline \multicolumn{8}{|c|}{ Panel C. TAIEX: partly-eliminated period, 2008 observations } \\
\hline \multirow{2}{*}{ Share volume vs. returns } & 2.591 & 0.826 & 0.072 & -0.112 & \multirow{2}{*}{-0.040} & \multirow{2}{*}{0.032} & \multirow{2}{*}{0.733} \\
\hline & $(14.784)^{\star \star \star}$ & $(71.393)^{\star \star *}$ & $(14.700)^{\star \star \star}$ & $(-14.759)^{\star \star \star}$ & & & \\
\hline \multirow{2}{*}{ Dollar volume vs. returns } & 3.131 & 0.827 & 0.085 & -0.123 & \multirow{2}{*}{-0.038} & \multirow{2}{*}{0.047} & \multirow{2}{*}{0.730} \\
\hline & $(14.639)^{\star \star \star}$ & $(71.229)^{\star \star \star}$ & $(15.308)^{\star \star \star}$ & $(-14.318)^{\star * *}$ & & & \\
\hline \multicolumn{8}{|c|}{ Panel D. TAIEX: entirely-eliminated period, 435 observations } \\
\hline \multirow{2}{*}{ Share volume vs. returns } & 3.411 & 0.775 & 0.124 & -0.203 & \multirow{2}{*}{-0.079} & \multirow{2}{*}{0.045} & \multirow{2}{*}{0.673} \\
\hline & $(8.088)^{\star \star \star}$ & $(28.258)^{\star \star *}$ & $(8.887)^{\star \star \star}$ & $(-9.175)^{\star \star \star}$ & & & \\
\hline \multirow{2}{*}{ Dollar volume vs. returns } & 6.220 & 0.657 & 0.137 & -0.232 & \multirow{2}{*}{-0.095} & \multirow{2}{*}{0.042} & 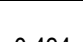 \\
\hline & $(9.911)^{\star \star \star}$ & $(19.190)^{\star \star \star}$ & $(7.955)^{\star \star \star}$ & $(-8.483)^{\star \star \star}$ & & & 0.494 \\
\hline
\end{tabular}

Notes: Those in parentheses are $t$-statistics for the intercept and the coefficients estimates. $*, * *$ and $* * *$ indicates significance at the $10 \%, 5 \%$ and $1 \%$ levels, respectively. The empirical model specified is $V_{t}=c+a \times V_{t-1}+b \times S R_{t}+\gamma \times D_{t} \times S R_{t}+\varepsilon_{t}$. $V_{t}$ is the trade volume in the trading day $t$. The natural logarithm of share and dollar turnovers are used as the trade volume. $S R_{t}$, calculated by log price change $100 \% \times \log \left(P_{t} / P_{t-1}\right)$, is the signed return over the trading day $t$ where $P_{t}$ is the price at time $t$ and so forth. $D_{t}$ is a dummy variable for the trading day $t$ that equals one for negative returns and zero for non-negative returns. Intercept $c$, coefficients $a, b$, and $\gamma$ are parameters of the regression. The slope estimates $b$ measure the correlation of volume associated with non-negative returns and $(b+\gamma)$ measure the correlation of volume associated with negative returns. If both the coefficients, $b$ and $\gamma$, are significant, the volume-return correlation is asymmetric. The asymmetry is evaluated by $b+(b+\gamma)$.

Table 4. GARCH $(1,1)$ estimates of volume-signed return correlation

\begin{tabular}{|c|c|c|c|c|c|c|c|c|c|c|}
\hline & $c$ & $a$ & $b$ & y & $\alpha_{0}$ & $\alpha_{1}$ & $\beta_{1}$ & $b+\gamma$ & $b+(b+\gamma)$ & Adj. $R^{2}$ \\
\hline \multicolumn{11}{|c|}{ Panel A. Taiwan 50 ETF: full-sample period, 2981 observations } \\
\hline \multirow{2}{*}{$\begin{array}{l}\text { Share volume } \\
\text { vs. returns }\end{array}$} & 3.413 & 0.602 & 0.213 & -0.440 & 0.005 & 0.031 & 0.953 & \multirow{2}{*}{-0.227} & \multirow{2}{*}{-0.014} & \multirow{2}{*}{0.498} \\
\hline & $(27.157)^{\star \star \star}$ & $(43.095)^{\star \star \star}$ & $(20.975)^{\star \star \star}$ & $(-26.931)^{\star \star \star}$ & $(3.418)^{\star \star \star}$ & $(4.973)^{\star \star \star}$ & $(106.807)^{\star \star \star}$ & & & \\
\hline \multirow{2}{*}{$\begin{array}{l}\text { Dollar volume } \\
\text { vs. returns }\end{array}$} & 4.730 & 0.624 & 0.200 & -0.406 & 0.005 & 0.032 & 0.951 & \multirow{2}{*}{-0.206} & \multirow{2}{*}{-0.006} & \multirow{2}{*}{0.496} \\
\hline & $(25.806)^{\star \star \star}$ & $(44.166)^{\star \star \star}$ & $(19.860)^{\star \star \star}$ & $(-24.709)^{\star \star \star}$ & $(3.559)^{\star \star *}$ & $(4.948)^{\star \star *}$ & $(102.520)^{\star * *}$ & & & \\
\hline \multicolumn{11}{|c|}{ Panel B. TAIEX: pre-eliminated period, 538 observations } \\
\hline \multirow{2}{*}{$\begin{array}{l}\text { Share volume } \\
\text { vs. returns }\end{array}$} & 2.362 & 0.840 & 0.105 & -0.109 & 0.013 & 0.162 & 0.528 & \multirow{2}{*}{-0.004} & \multirow{2}{*}{0.101} & \multirow{2}{*}{0.707} \\
\hline & $(6.791)^{\star \star \star}$ & $(36.520)^{\star \star \star}$ & $(11.595)^{\star \star \star}$ & $(-8.333)^{\star \star \star}$ & $(2.630)^{\star \star *}$ & $(4.208)^{\star \star \star}$ & $(3.856)^{* \star *}$ & & & \\
\hline \multirow{2}{*}{$\begin{array}{l}\text { Dollar volume } \\
\text { vs. returns }\end{array}$} & 2.830 & 0.841 & 0.114 & -0.111 & 0.014 & 0.171 & 0.545 & \multirow{2}{*}{0.004} & \multirow{2}{*}{0.118} & \multirow{2}{*}{0.699} \\
\hline & $(7.099)^{\star \star \star}$ & $(38.249)^{\star \star \star}$ & $(12.270)^{\star \star \star}$ & $(-8.404)^{\star \star \star}$ & $(2.605)^{\star \star \star}$ & $(4.529)^{\star \star \star}$ & $(4.185)^{\star \star \star}$ & & & \\
\hline
\end{tabular}


Table 4 (cont.). GARCH $(1,1)$ estimates of volume-signed return correlation

\begin{tabular}{|c|c|c|c|c|c|c|c|c|c|c|}
\hline & $c$ & a & $b$ & Y & $\alpha_{0}$ & $\alpha_{1}$ & $\beta_{1}$ & $b+\gamma$ & $b+(b+\gamma)$ & Adj. $R^{2}$ \\
\hline \multicolumn{11}{|c|}{ Panel C. TAIEX: partly-eliminated period, 2008 observations (ARCH estimates) } \\
\hline \multirow{2}{*}{$\begin{array}{l}\text { Share volume } \\
\text { vs. returns }\end{array}$} & 2.487 & 0.833 & 0.072 & -0.110 & 0.021 & 0.052 & & \multirow{2}{*}{-0.038} & \multirow{2}{*}{0.034} & \multirow{2}{*}{0.733} \\
\hline & $(13.905)^{\star \star \star}$ & $(70.508)^{\star \star \star}$ & $(20.110)^{\star \star *}$ & $(-17.906)^{\star \star \star}$ & $(25.634)^{\star \star \star}$ & $(1.786)^{\star}$ & & & & \\
\hline \multirow{2}{*}{$\begin{array}{l}\text { Dollar volume } \\
\text { vs. returns }\end{array}$} & 2.996 & 0.834 & 0.086 & -0.122 & 0.027 & 0.061 & & \multirow{2}{*}{-0.036} & \multirow{2}{*}{0.050} & \multirow{2}{*}{0.730} \\
\hline & $(13.802)^{\star \star \star}$ & $(70.748)^{\star * *}$ & $(21.136)^{\star * \star}$ & $(-17.358)^{\star * *}$ & $(27.084)^{\star * \star}$ & $(2.458)^{\star \star}$ & & & & \\
\hline \multicolumn{11}{|c|}{ Panel D. TAIEX: entirely-eliminated period, 435 observations } \\
\hline \multirow{2}{*}{$\begin{array}{l}\text { Share volume } \\
\text { vs. returns }\end{array}$} & 3.169 & 0.790 & 0.124 & -0.194 & 0.004 & 0.175 & 0.433 & \multirow{2}{*}{-0.071} & \multirow{2}{*}{0.053} & \multirow{2}{*}{0.673} \\
\hline & $(7.004)^{\star \star \star}$ & $(26.834)^{\star \star \star}$ & $(8.858)^{\star \star \star}$ & $(-8.764)^{\star \star \star}$ & $(2.313)^{\star *}$ & $(2.262)^{\star *}$ & $(2.145)^{\star \star}$ & & & \\
\hline \multirow{2}{*}{$\begin{array}{l}\text { Dollar volume } \\
\text { vs. returns }\end{array}$} & 5.913 & 0.674 & 0.136 & -0.223 & 0.006 & 0.136 & 0.518 & \multirow{2}{*}{-0.087} & \multirow{2}{*}{0.049} & \multirow{2}{*}{0.493} \\
\hline & $(9.043)^{\star * \star}$ & $(18.854)^{\star \star \star}$ & $(8.908)^{\star \star *}$ & $(-9.351)^{\star \star \star}$ & $(2.150)^{\star *}$ & $(2.095)^{\star \star}$ & $(2.679)^{* * *}$ & & & \\
\hline
\end{tabular}

Notes: The empirical model specified is $V_{t}=c+a \times V_{t-1}+b \times S R_{t}+\gamma \times D_{t} \times S R_{t}+\varepsilon_{t}$, where $\varepsilon_{t} \sim N\left(0, h_{t}\right), h_{t}=\alpha_{0}+\alpha_{1} \times \varepsilon_{t-1}^{2}+\beta_{l} \times$ $h_{t-1} . V_{t}$ is the trade volume in the trading day $t$. The natural logarithm of share and dollar turnovers are used as the trade volume. $S R_{t}$, calculated by $\log$ price change $100 \% \times \log \left(P_{t} / P_{t-1}\right)$, is the signed return over the trading day $t$ where $P_{t}$ is the price at time $t$ and so forth. $D_{t}$ is a dummy variable for the trading day $t$ that equals one for negative returns and zero for non-negative returns. Intercept $c$, coefficients $a, b$, and $\gamma$ are parameters of the model. Intercept $\alpha_{0}$, coefficients $\alpha_{1}$ and $\beta_{1}$ are parameters of the conditional variance equation for the error term. The slope estimates $b$ measure the correlation of volume associated with non-negative returns and $(b+\gamma)$ measure the correlation of volume associated with negative returns. If both the coefficients, $b$ and $\gamma$, are significant, the volumereturn correlation is asymmetric. The asymmetry is evaluated by $b+(b+\gamma)$. Those in parentheses are $z$-statistics for the intercept and the coefficients estimates. $* * *$ and $* * *$ indicates significance at the $10 \%, 5 \%$ and $1 \%$ levels, respectively. In the partlyeliminated period, since the autoregressive GARCH terms are not significant, I use the ARCH(1), i.e. GARCH( 0,1$)$, model to estimate. Accordingly, there are no $\beta_{1}$ estimates in this period.

Table 5. Quantile regression estimates of volume-signed return correlation for Taiwan 50 ETF in the full-sample period

\begin{tabular}{|c|c|c|c|c|c|c|}
\hline \multicolumn{7}{|c|}{ Panel A. Share volume vs. returns } \\
\hline Quantile & $c$ & $a$ & $b$ & y & $b+y$ & $b+(b+y)$ \\
\hline \multirow{2}{*}{0.01} & 0.984 & 0.720 & 0.199 & -0.353 & \multirow{2}{*}{-0.154} & \multirow{2}{*}{0.045} \\
\hline & $(1.642)$ & $(10.531)^{\star \star \star}$ & $(4.613)^{\star \star \star}$ & $(-4.523)^{\star \star \star}$ & & \\
\hline \multirow{2}{*}{0.05} & 1.758 & 0.683 & 0.186 & -0.391 & \multirow{2}{*}{-0.205} & \multirow{2}{*}{-0.019} \\
\hline & $(4.844)^{\star * *}$ & $(16.656)^{\star * *}$ & $(5.491)^{\star * \star}$ & $(-7.136)^{\star \star *}$ & & \\
\hline \multirow{2}{*}{0.10} & 1.997 & 0.684 & 0.200 & -0.398 & \multirow{2}{*}{-0.198} & \multirow{2}{*}{0.002} \\
\hline & $(8.656)^{\star \star \star}$ & $(26.673)^{\star \star \star}$ & $(8.123)^{\star \star \star}$ & $(-9.823)^{\star \star \star}$ & & \\
\hline \multirow{2}{*}{0.15} & 2.277 & 0.669 & 0.193 & -0.377 & \multirow{2}{*}{-0.183} & \multirow{2}{*}{0.010} \\
\hline & $(9.329)^{\star \star \star}$ & $(24.433)^{\star \star \star}$ & $(9.861)^{\star \star \star}$ & $(-9.457)^{\star \star \star}$ & & \\
\hline \multirow{2}{*}{0.20} & 2.476 & 0.659 & 0.198 & -0.415 & \multirow{2}{*}{-0.217} & \multirow{2}{*}{-0.019} \\
\hline & $(11.892)^{\star \star \star}$ & $(28.134)^{\star \star \star}$ & $(9.901)^{\star \star \star}$ & $(-11.334)^{\star \star \star}$ & & \\
\hline \multirow{2}{*}{0.25} & 2.631 & 0.652 & 0.199 & -0.410 & \multirow{2}{*}{-0.211} & \multirow{2}{*}{-0.013} \\
\hline & $(17.143)^{\star \star \star}$ & $(38.925)^{\star \star \star}$ & $(13.001)^{\star \star \star}$ & $(-17.195)^{\star \star \star}$ & & \\
\hline \multirow{2}{*}{0.30} & 2.806 & 0.641 & 0.198 & -0.408 & \multirow{2}{*}{-0.210} & \multirow{2}{*}{-0.011} \\
\hline & $(17.814)^{\star \star \star}$ & $(37.410)^{\star \star *}$ & $(10.221)^{\star \star \star}$ & $(-13.195)^{\star \star \star}$ & & \\
\hline \multirow{2}{*}{0.35} & 2.916 & 0.636 & 0.203 & -0.421 & \multirow{2}{*}{-0.218} & \multirow{2}{*}{-0.015} \\
\hline & $(20.289)^{\star \star \star}$ & $(40.510)^{\star \star \star}$ & $(11.079)^{\star \star \star}$ & $(-12.762)^{\star \star \star}$ & & \\
\hline \multirow{2}{*}{0.40} & 3.132 & 0.619 & 0.205 & -0.434 & \multirow{2}{*}{-0.228} & \multirow{2}{*}{-0.023} \\
\hline & $(17.006)^{\star \star \star}$ & $(31.887)^{\star \star \star}$ & $(9.782)^{\star \star *}$ & $(-12.919)^{\star \star \star}$ & & \\
\hline \multirow{2}{*}{0.45} & 3.327 & 0.605 & 0.211 & -0.446 & 0035 & 0024 \\
\hline & $(21.027)^{\star \star \star}$ & $(34.917)^{\star \star \star}$ & $(10.186)^{\star \star \star}$ & $(-14.823)^{\star \star \star}$ & -0.235 & -0.024 \\
\hline 050 & 3.341 & 0.611 & 0.214 & -0.438 & 020 & م010 \\
\hline 0.50 & $(20.582)^{\star \star \star}$ & $(33.547)^{\star \star \star}$ & $(9.503)^{\star \star \star}$ & $(-14.016)^{\star \star \star}$ & -0.224 & -0.010 \\
\hline 055 & 3.448 & 0.604 & 0.233 & -0.465 & 0231 & 0000 \\
\hline 0.55 & $(22.820)^{\star \star \star}$ & $(36.101)^{\star \star \star}$ & $(11.562)^{\star \star \star}$ & $(-15.975)^{\star \star \star}$ & -0.231 & 0.002 \\
\hline 060 & 3.461 & 0.609 & 0.247 & -0.481 & -0235 & 0.012 \\
\hline 0.60 & $(24.676)^{\star \star \star}$ & $(38.500)^{\star \star \star}$ & $(10.645)^{\star \star \star}$ & $(-13.542)^{\star \star \star}$ & -0.235 & 0.012 \\
\hline & 3.521 & 0.609 & 0.251 & -0.497 & -0246 & \\
\hline 0.65 & $(24.279)^{\star \star \star}$ & $(38.688)^{\star \star \star}$ & $(11.249)^{\star \star \star}$ & $(-13.264)^{\star \star \star}$ & -0.246 & 0.006 \\
\hline 070 & 3.665 & 0.598 & 0.277 & -0.538 & 0261 & 0017 \\
\hline 0.70 & $(26.612)^{\star \star \star}$ & $(39.824)^{\star \star \star}$ & $(13.485)^{\star \star \star}$ & $(-17.201)^{\star \star \star}$ & -0.261 & 0.017 \\
\hline 075 & 3.845 & 0.586 & 0.282 & -0.551 & - & 2012 \\
\hline 0.75 & $(22.656)^{\star \star \star}$ & $(32.392)^{\star \star \star}$ & $(15.103)^{\star \star \star}$ & $(-16.475)^{\star \star \star}$ & -0.269 & 0.012 \\
\hline
\end{tabular}


Table 5 (cont.). Quantile regression estimates of volume-signed return correlation for Taiwan 50 ETF in the full-sample period

\begin{tabular}{|c|c|c|c|c|c|c|}
\hline Quantile & $c$ & $a$ & $b$ & $y$ & $b+y$ & $b+(b+y)$ \\
\hline \multicolumn{7}{|c|}{ Panel A. Share volume vs. returns } \\
\hline \multirow{2}{*}{0.80} & 3.883 & 0.591 & 0.268 & -0.542 & \multirow{2}{*}{-0.275} & \multirow{2}{*}{-0.007} \\
\hline & $(25.153)^{\star \star \star}$ & $(34.998)^{\star \star \star}$ & $(11.598)^{\star \star \star}$ & $(-13.778)^{\star \star \star}$ & & \\
\hline \multirow{2}{*}{0.85} & 4.075 & 0.578 & 0.287 & -0.580 & \multirow{2}{*}{-0.293} & \multirow{2}{*}{-0.006} \\
\hline & $(21.813)^{\star \star \star}$ & $(28.636)^{\star \star \star}$ & $(14.591)^{\star \star \star}$ & $(-16.076)^{\star \star \star}$ & & \\
\hline \multirow{2}{*}{0.90} & 4.548 & 0.540 & 0.274 & -0.563 & \multirow{2}{*}{-0.289} & \multirow{2}{*}{-0.015} \\
\hline & $(25.116)^{\star \star \star}$ & $(27.933)^{\star \star \star}$ & $(11.705)^{\star \star \star}$ & $(-14.505)^{\star \star \star}$ & & \\
\hline \multirow{2}{*}{0.95} & 5.014 & 0.508 & 0.271 & -0.589 & \multirow{2}{*}{-0.318} & \multirow{2}{*}{-0.046} \\
\hline & $(19.659)^{\star \star \star}$ & $(19.125)^{\star \star \star}$ & $(10.646)^{\star \star \star}$ & $(-11.099)^{\star \star \star}$ & & \\
\hline \multirow{2}{*}{0.99} & 5.946 & 0.436 & 0.307 & -0.626 & \multirow{2}{*}{-0.319} & \multirow{2}{*}{-0.012} \\
\hline & $(15.889)^{+*+*}$ & $(10.616)^{*+1+}$ & $(4.400)^{t+m}$ & $(-6.772)^{+*+t}$ & & \\
\hline \multicolumn{7}{|c|}{ Panel B. Dollar volume vs. returns } \\
\hline \multirow{2}{*}{0.01} & 1.700 & 0.752 & 0.198 & -0.327 & & 0060 \\
\hline & $(1.998)^{\star \star}$ & $(11.155)^{\star \star \star}$ & $(5.042)^{\star \star \star}$ & $(-4.830)^{\star \star \star}$ & -0.129 & 0.069 \\
\hline 0.05 & 2.282 & 0.742 & 0.169 & -0.334 & -0.166 & 0.003 \\
\hline 0.05 & $(4.640)^{\star \star \star}$ & $(19.519)^{\star \star \star}$ & $(5.147)^{\star \star \star}$ & $(-5.784)^{\star \star \star}$ & -0.100 & 0.003 \\
\hline 010 & 3.092 & 0.698 & 0.174 & -0.361 & -0187 & -0014 \\
\hline 0.10 & $(10.673)^{\star \star *}$ & $(31.459)^{* * *}$ & $(7.781)^{\star \star \star}$ & $(-9.006)^{\star \star \star}$ & $-0.18 /$ & -0.014 \\
\hline & 3.209 & 0.698 & 0.178 & -0.355 & & \\
\hline 0.15 & $(9.898)^{\star \star \star}$ & $(27.899)^{\star \star \star}$ & $(8.715)^{\star \star \star}$ & $(-9.725)^{\star \star \star}$ & $-0.1 / 6$ & 0.001 \\
\hline & 3.491 & 0.686 & 0.181 & -0.365 & -0184 & -0003 \\
\hline 0.20 & $(13.172)^{\star \star \star}$ & $(33.741)^{\star \star \star}$ & $(9.254)^{\star \star *}$ & $(-11.402)^{\star \star \star}$ & -0.184 & -0.003 \\
\hline 025 & 3.699 & 0.677 & 0.189 & -0.376 & -0187 & 0003 \\
\hline 0.25 & $(15.009)^{\star * *}$ & $(35.777)^{\star \star *}$ & $(11.522)^{\star \star \star}$ & $(-13.652)^{\star \star *}$ & $-0.18 /$ & 0.003 \\
\hline 030 & 3.872 & 0.669 & 0.192 & -0.385 & -0193 & $-\cap 001$ \\
\hline 0.30 & $(19.480)^{\star \star \star}$ & $(44.885)^{\star \star \star}$ & $(11.271)^{\star \star \star}$ & $(-13.343)^{\star \star \star}$ & -0.190 & -0.001 \\
\hline 025 & 4.019 & 0.663 & 0.189 & -0.390 & - 0201 & $=0012$ \\
\hline 0.35 & $(21.884)^{\star \star \star}$ & $(47.804)^{\star \star \star *}$ & $(12.523)^{\star \star \star}$ & $(-14.007)^{\star \star \star}$ & -0.201 & -0.012 \\
\hline 040 & 4.346 & 0.643 & 0.189 & -0.394 & -0205 & -0016 \\
\hline 0.40 & $(16.848)^{\star \star \star}$ & $(33.210)^{\star \star \star}$ & $(9.325)^{\star \star \star}$ & $(-11.897)^{\star \star \star}$ & -0.205 & -0.016 \\
\hline & 4.636 & 0.626 & 0.190 & -0.392 & -0202 & -0012 \\
\hline 0.45 & $(18.562)^{\star \star \star}$ & $(33.220)^{* * *}$ & $(7.908)^{\star * *}$ & $(-11.425)^{\star \star \star}$ & -0.202 & -0.012 \\
\hline 050 & 4.626 & 0.632 & 0.201 & -0.408 & -0207 & $-0,006$ \\
\hline 0.50 & $(20.144)^{\star \star \star}$ & $(36.236)^{\star \star \star}$ & $(9.306)^{\star \star \star}$ & $(-12.201)^{\star \star \star}$ & $-0.20 /$ & -0.006 \\
\hline 055 & 4.675 & 0.632 & 0.227 & -0.437 & -0210 & 0.016 \\
\hline 0.55 & $(21.694)^{\star \star \star}$ & $(38.044)^{\star \star \star}$ & $(9.841)^{\star \star \star}$ & $(-12.796)^{\star \star \star}$ & -0.210 & 0.016 \\
\hline 060 & 4.675 & 0.636 & 0.234 & -0.449 & -0215 & 0019 \\
\hline 0.60 & $(21.417)^{\star \star \star}$ & $(37.917)^{\star * \star}$ & $(10.685)^{\star * *}$ & $(-13.352)^{\star \star *}$ & -0.215 & 0.019 \\
\hline 065 & 4.831 & 0.629 & 0.246 & -0.477 & 0021 & 0011 \\
\hline 0.65 & $(22.609)^{\star \star *}$ & $(38.489)^{\star * \star}$ & $(11.208)^{\star * *}$ & $(-13.321)^{\star * *}$ & -0.231 & 0.014 \\
\hline 070 & 4.948 & 0.623 & 0.274 & -0.523 & -0249 & 0025 \\
\hline 0.10 & $(26.514)^{\star \star \star}$ & $(43.301)^{\star \star \star}$ & $(11.814)^{\star \star \star}$ & $(-14.165)^{\star \star \star}$ & -0.249 & 0.025 \\
\hline 075 & 5.014 & 0.623 & 0.288 & -0.553 & -0266 & ?ח?? \\
\hline 0.75 & $(22.887)^{\star \star \star}$ & $(37.536)^{\star \star \star}$ & $(14.277)^{\star \star \star}$ & $(-16.646)^{\star \star \star}$ & -0.266 & 0.022 \\
\hline 080 & 5.315 & 0.606 & 0.283 & -0.539 & -0256 & 0028 \\
\hline 0.80 & $(23.346)^{\star \star \star}$ & $(35.665)^{\star \star \star}$ & $(13.392)^{\star \star \star}$ & $(-16.167)^{\star \star \star}$ & -0.256 & 0.028 \\
\hline 085 & 5.376 & 0.608 & 0.287 & -0.560 & - 273 & 0013 \\
\hline 0.85 & $(20.706)^{\star \star \star}$ & $(30.886)^{\star \star \star}$ & $(13.931)^{\star \star \star}$ & $(-16.327)^{\star \star \star}$ & $-0.2 / 3$ & 0.013 \\
\hline , & 6.049 & 0.566 & 0.287 & -0.559 & -0.272 & 0.015 \\
\hline 0.90 & $(20.550)^{\star \star \star}$ & $(25.817)^{\star \star \star}$ & $(11.839)^{\star \star \star}$ & $(-12.887)^{\star \star \star}$ & $-0.2 / 2$ & 0.015 \\
\hline 005 & 6.556 & 0.540 & 0.283 & -0.610 & 0027 & 0010 \\
\hline 0.95 & $(18.820)^{\star \star \star}$ & $(20.545)^{\star \star *}$ & $(11.004)^{\star * *}$ & $(-10.905)^{\star \star \star}$ & -0.321 & -0.043 \\
\hline 0.99 & 7.933 & 0.462 & 0.247 & -0.532 & & \\
\hline 0.99 & $(13.883)^{\star \star \star}$ & $(10.579)^{\star \star \star}$ & $(4.135)^{\star \star \star}$ & $(-6.023)^{\star \star \star}$ & -0.285 & -0.038 \\
\hline
\end{tabular}

Notes: Those in parentheses are $t$-statistics for the intercept and the coefficients estimates. $* * *$ and $* * *$ indicates significance at the $10 \%, 5 \%$ and $1 \%$ levels, respectively. 
Table 6. Quantile regression estimates of volume-signed return correlation for TAIEX in the pre-eliminated period

\begin{tabular}{|c|c|c|c|c|c|c|}
\hline Quantile & $c$ & $a$ & $b$ & y & $b+y$ & $b+(b+\gamma)$ \\
\hline \multicolumn{7}{|c|}{ Panel A. Share volume vs. returns } \\
\hline \multirow{2}{*}{0.01} & 1.295 & 0.886 & 0.056 & 0.031 & \multirow{2}{*}{0.087} & \multirow{2}{*}{0.143} \\
\hline & $(0.689)$ & $(7.127)^{\star * *}$ & $(2.379)^{\star \star}$ & $(0.579)$ & & \\
\hline \multirow{2}{*}{0.05} & 3.165 & 0.770 & 0.075 & -0.016 & \multirow{2}{*}{0.059} & \multirow{2}{*}{0.133} \\
\hline & $(3.900)^{\star \star \star}$ & $(14.588)^{\star \star \star}$ & $(2.856)^{\star \star \star}$ & $(-0.296)$ & & \\
\hline \multirow{2}{*}{0.10} & 3.109 & 0.776 & 0.079 & -0.049 & \multirow{2}{*}{0.030} & \multirow{2}{*}{0.109} \\
\hline & $(5.378)^{* * *}$ & $(20.632)^{\star * *}$ & $(3.343)^{\star * *}$ & $(-0.886)$ & & \\
\hline \multirow{2}{*}{0.15} & 3.138 & 0.776 & 0.092 & -0.085 & \multirow{2}{*}{0.007} & \multirow{2}{*}{0.098} \\
\hline & $(5.458)^{\star \star \star}$ & $(20.466)^{\star \star \star}$ & $(5.237)^{\star \star \star}$ & $(-2.107)^{\star \star}$ & & \\
\hline \multirow{2}{*}{0.20} & 2.929 & 0.792 & 0.092 & -0.082 & \multirow{2}{*}{0.011} & \multirow{2}{*}{0.103} \\
\hline & $(4.371)^{\star \star \star}$ & $(17.783)^{\star \star \star}$ & $(6.740)^{\star \star \star}$ & $(-2.509)^{\star *}$ & & \\
\hline \multirow{2}{*}{0.25} & 2.648 & 0.814 & 0.084 & -0.075 & \multirow{2}{*}{0.009} & 0000 \\
\hline & $(4.812)^{\star * \star}$ & $(22.392)^{\star * *}$ & $(6.436)^{\star \star *}$ & $(-2.722)^{\star \star \star}$ & & 0.090 \\
\hline 030 & 2.510 & 0.824 & 0.089 & -0.091 & 0003 & 0080 \\
\hline 0.30 & $(4.217)^{\star \star \star}$ & $(20.937)^{\star \star \star}$ & $(4.622)^{\star \star \star}$ & $(-3.102)^{\star \star \star}$ & -0.003 & 0.086 \\
\hline 025 & 2.605 & 0.820 & 0.084 & -0.086 & 000 & $000 ?$ \\
\hline 0.00 & $(4.082)^{\star \star \star}$ & $(19.449)^{\star \star \star}$ & $(3.264)^{\star \star \star}$ & $(-2.442)^{\star \star}$ & $-0.00<$ & 0.000 \\
\hline 010 & 2.058 & 0.857 & 0.118 & -0.141 & 000 & 000 \\
\hline 0.40 & $(3.655)^{* * *}$ & $(22.928)^{\star * *}$ & $(4.502)^{\star \star *}$ & $(-4.011)^{\star \star *}$ & $-0.0<0$ & 0.090 \\
\hline 015 & 1.922 & 0.867 & 0.132 & -0.156 & 000 & 0107 \\
\hline 0.45 & $(4.305)^{\star \star \star}$ & $(29.181)^{\star \star \star}$ & $(6.280)^{\star \star \star}$ & $(-5.400)^{\star \star \star}$ & -0.024 & 0.107 \\
\hline 050 & 2.056 & 0.860 & 0.130 & -0.155 & 0025 & 0105 \\
\hline 0.00 & $(4.946)^{\star \star \star}$ & $(31.267)^{\star \star \star}$ & $(8.110)^{\star \star \star}$ & $(-6.671)^{\star \star \star}$ & $-0.0<0$ & 0.105 \\
\hline 055 & 1.908 & 0.871 & 0.130 & -0.156 & 000 & 0100 \\
\hline 0.55 & $(4.444)^{\star \star \star}$ & $(30.895)^{\star \star \star}$ & $(9.049)^{\star \star \star}$ & $(-7.104)^{\star \star \star}$ & $-0.0<0$ & 0.105 \\
\hline 000 & 2.112 & 0.859 & 0.126 & -0.152 & 000 & 0100 \\
\hline 0.60 & $(4.751)^{\star \star \star}$ & $(29.596)^{\star \star \star}$ & $(7.264)^{\star \star \star}$ & $(-6.052)^{\star \star \star}$ & -0.026 & 0.100 \\
\hline 095 & 2.253 & 0.851 & 0.126 & -0.154 & 0 & 007 \\
\hline .00 & $(5.848)^{\star \star \star}$ & $(33.927)^{\star * *}$ & $(6.522)^{\star \star \star}$ & $(-5.717)^{\star \star \star}$ & $-0.0<0$ & 0.091 \\
\hline 070 & 2.265 & 0.851 & 0.141 & -0.173 & 000 & 010 \\
\hline 0.10 & $(7.006)^{\star * \star}$ & $(40.189)^{\star * *}$ & $(7.860)^{\star \star *}$ & $(-6.986)^{\star * \star}$ & -0.002 & 0.109 \\
\hline 075 & 2.514 & 0.837 & 0.147 & -0.178 & 021 & 0110 \\
\hline 0.15 & $(7.713)^{\star \star \star}$ & $(38.415)^{\star \star \star}$ & $(7.902)^{\star \star \star}$ & $(-6.914)^{\star * \star}$ & -0.031 & 0.116 \\
\hline مอ & 2.258 & 0.855 & 0.148 & -0.178 & 021 & 0117 \\
\hline 0.00 & $(5.870)^{\star \star \star}$ & $(33.351)^{\star * *}$ & $(8.113)^{\star \star \star}$ & $(-6.761)^{\star \star *}$ & -0.001 & 0.111 \\
\hline 005 & 2.559 & 0.838 & 0.140 & -0.170 & 0021 & 010 \\
\hline 0.85 & $(6.630)^{\star \star \star}$ & $(33.009)^{\star \star \star}$ & $(9.117)^{\star \star \star}$ & $(-6.540)^{\star \star \star}$ & -0.001 & 0.109 \\
\hline م00 & 3.074 & 0.808 & 0.123 & -0.147 & 0020 & 0100 \\
\hline 0.90 & $(5.568)^{\star \star \star}$ & $(22.633)^{\star \star \star}$ & $(6.664)^{\star \star \star}$ & $(-3.771)^{\star \star \star}$ & -0.023 & 0.100 \\
\hline 005 & 4.139 & 0.745 & 0.093 & -0.137 & 0040 & 000 \\
\hline 0.95 & $(4.968)^{\star \star \star}$ & $(13.834)^{\star \star *}$ & $(3.480)^{\star \star \star}$ & $(-2.288)^{\star *}$ & -0.044 & 0.049 \\
\hline م00 & 5.970 & 0.629 & 0.112 & -0.433 & 0020 & 0000 \\
\hline 0.99 & $(5.688)^{\star \star *}$ & $(9.253)^{\star \star *}$ & $(2.810)^{\star * *}$ & $(-2.662)^{\star \star \star}$ & -0.321 & -0.209 \\
\hline Panel B. Doll & vs. returns & & & & & \\
\hline 001 & 1.511 & 0.892 & 0.046 & 0.056 & 0100 & 0110 \\
\hline 0.01 & $(0.967)$ & $(10.326)^{* * *}$ & $(1.448)$ & $(1.040)$ & 0.102 & 0.148 \\
\hline 005 & 3.621 & 0.783 & 0.076 & 0.028 & 0100 & 0181 \\
\hline 0.05 & $(4.683)^{\star * *}$ & $(18.681)^{\star \star \star}$ & $(2.209)^{\star \star}$ & $(0.471)$ & 0.105 & 0.181 \\
\hline 010 & 3.459 & 0.793 & 0.090 & -0.034 & 0057 & 0147 \\
\hline 0.10 & $(4.424)^{\star \star \star}$ & $(18.691)^{\star \star \star}$ & $(3.750)^{\star \star \star}$ & $(-0.557)$ & $0.05 \pi$ & 0.147 \\
\hline 011 & 4.075 & 0.762 & 0.092 & -0.073 & 0010 & 0111 \\
\hline 0.15 & $(5.433)^{\star \star \star}$ & $(18.532)^{\star \star \star}$ & $(5.457)^{\star \star \star}$ & $(-1.731)^{\star}$ & 0.019 & 0.111 \\
\hline م20 & 3.558 & 0.792 & 0.094 & -0.070 & 002 & 0110 \\
\hline 0.20 & $(4.476)^{\star * \star}$ & $(17.990)^{\star \star \star}$ & $(5.462)^{\star \star \star}$ & $(-2.181)^{\star \star}$ & 0.025 & 0.119 \\
\hline
\end{tabular}


Table 6 (cont.). Quantile regression estimates of volume-signed return correlation for TAIEX in the pre-eliminated period

\begin{tabular}{|c|c|c|c|c|c|c|}
\hline Quantile & c & a & $b$ & y & $b+y$ & $b+(b+y)$ \\
\hline \multicolumn{7}{|c|}{ Panel B. Dollar volume vs. returns } \\
\hline \multirow{2}{*}{0.25} & 3.083 & 0.820 & 0.098 & -0.082 & \multirow{2}{*}{0.016} & \multirow{2}{*}{0.114} \\
\hline & $(4.362)^{\star \star \star}$ & $(21.163)^{\star \star \star}$ & $(5.438)^{\star \star \star}$ & $(-2.609)^{\star \star \star}$ & & \\
\hline \multirow{2}{*}{0.30} & 3.072 & 0.823 & 0.097 & -0.088 & \multirow{2}{*}{0.009} & \multirow{2}{*}{0.106} \\
\hline & $(4.254)^{\star \star \star}$ & $(20.845)^{\star \star \star}$ & $(4.421)^{\star \star \star}$ & $(-2.522)^{\star \star}$ & & \\
\hline \multirow{2}{*}{0.35} & 3.029 & 0.826 & 0.098 & -0.094 & \multirow{2}{*}{0.004} & \multirow{2}{*}{0.102} \\
\hline & $(4.058)^{\star \star \star}$ & $(20.106)^{\star \star \star}$ & $(3.595)^{\star \star \star}$ & $(-2.546)^{\star \star}$ & & \\
\hline \multirow{2}{*}{0.40} & 2.261 & 0.870 & 0.119 & -0.127 & \multirow{2}{*}{-0.008} & \multirow{2}{*}{0.111} \\
\hline & $(3.314)^{\star \star \star}$ & $(23.063)^{\star \star \star}$ & $(3.952)^{\star \star \star}$ & $(-3.387)^{\star \star \star}$ & & \\
\hline \multirow{2}{*}{0.45} & 2.633 & 0.850 & 0.145 & -0.158 & \multirow{2}{*}{-0.013} & \multirow{2}{*}{0.132} \\
\hline & $(4.259)^{\star \star \star}$ & $(24.733)^{\star \star \star}$ & $(5.292)^{\star \star \star}$ & $(-4.563)^{\star \star \star}$ & & \\
\hline \multirow{2}{*}{0.50} & 2.122 & 0.879 & 0.150 & -0.166 & \multirow{2}{*}{-0.016} & \multirow{2}{*}{0.134} \\
\hline & $(3.889)^{\star \star \star}$ & $(28.978)^{\star \star \star}$ & $(6.697)^{\star \star \star}$ & $(-5.418)^{\star \star \star}$ & & \\
\hline \multirow{2}{*}{0.55} & 1.940 & 0.890 & 0.143 & -0.158 & \multirow{2}{*}{-0.015} & \multirow{2}{*}{0.128} \\
\hline & $(4.002)^{* \star *}$ & $(33.516)^{\star \star \star}$ & $(7.407)^{\star \star \star}$ & $(-5.630)^{\star \star \star}$ & & \\
\hline \multirow{2}{*}{0.60} & 2.416 & 0.866 & 0.148 & -0.167 & \multirow{2}{*}{-0.019} & \multirow{2}{*}{0.130} \\
\hline & $(4.767)^{\star \star \star}$ & $(31.564)^{\star \star \star}$ & $(8.127)^{\star \star \star}$ & $(-6.098)^{\star * \star}$ & & \\
\hline \multirow{2}{*}{0.65} & 2.769 & 0.848 & 0.144 & -0.157 & \multirow{2}{*}{-0.013} & \multirow{2}{*}{0.130} \\
\hline & $(5.388)^{\star \star \star}$ & $(30.536)^{\star \star \star}$ & $(8.517)^{\star \star \star}$ & $(-5.895)^{\star \star \star}$ & & \\
\hline \multirow{2}{*}{0.70} & 2.755 & 0.850 & 0.163 & -0.190 & 0027 & 0135 \\
\hline & $(5.397)^{\star \star \star}$ & $(30.917)^{\star \star \star}$ & $(9.787)^{\star \star \star}$ & $(-6.792)^{\star \star \star}$ & -0.021 & 0.135 \\
\hline 075 & 3.336 & 0.820 & 0.145 & -0.165 & - & 0126 \\
\hline 0.10 & $(6.014)^{\star \star \star}$ & $(27.352)^{\star \star \star}$ & $(9.465)^{\star \star \star}$ & $(-6.049)^{\star * \star}$ & $-0.0<0$ & $0.1<0$ \\
\hline م80 & 3.426 & 0.816 & 0.149 & -0.174 & 0025 & \\
\hline 0.80 & $(5.892)^{\star \star \star}$ & $(25.401)^{\star \star \star}$ & $(9.721)^{\star \star \star}$ & $(-6.670)^{\star \star \star}$ & -0.025 & 0.123 \\
\hline 085 & 3.105 & 0.836 & 0.146 & -0.186 & 0040 & 0106 \\
\hline 0.85 & $(5.184)^{\star \star \star}$ & $(25.269)^{\star \star \star}$ & $(8.295)^{\star \star \star}$ & $(-5.793)^{\star \star \star}$ & -0.040 & 0.100 \\
\hline 000 & 3.598 & 0.811 & 0.139 & -0.186 & -0047 & م09? \\
\hline 0.90 & $(5.352)^{\star \star \star}$ & $(22.184)^{\star \star \star}$ & $(6.018)^{\star \star \star}$ & $(-4.474)^{\star \star \star}$ & -0.041 & .092 \\
\hline 0.5 & 4.293 & 0.778 & 0.160 & -0.233 & 0073 & 0097 \\
\hline 0.95 & $(5.315)^{\star \star \star}$ & $(17.808)^{\star \star \star}$ & $(4.898)^{\star \star \star}$ & $(-3.919)^{\star \star \star}$ & -0.013 & 0.081 \\
\hline 099 & 5.872 & 0.694 & 0.190 & -0.590 & 0400 & 0211 \\
\hline 0.99 & $(6.062)^{\star \star \star}$ & $(13.076)^{\star \star \star}$ & $(3.987)^{\star \star \star}$ & $(-3.137)^{\star \star \star}$ & -0.400 & -0.211 \\
\hline
\end{tabular}

Notes: Those in parentheses are $t$-statistics for the intercept and the coefficients estimates. $*, * *$ and $* * *$ indicates significance at the $10 \%, 5 \%$ and $1 \%$ levels, respectively.

Table 7. Quantile regression estimates of volume-signed return correlation for TAIEX in the partly-eliminated period

\begin{tabular}{|c|c|c|c|c|c|c|}
\hline Quantile & $c$ & $a$ & $b$ & y & $b+y$ & $b+(b+\gamma)$ \\
\hline \multicolumn{7}{|c|}{ Panel A. Share volume vs. returns } \\
\hline \multirow{2}{*}{0.01} & 3.166 & 0.765 & 0.036 & -0.084 & \multirow{2}{*}{-0.048} & \multirow{2}{*}{-0.012} \\
\hline & $(7.257)^{\star \star \star}$ & $(26.932)^{\star \star *}$ & $(4.302)^{\star \star \star}$ & $(-6.994)^{\star \star \star}$ & & \\
\hline \multirow{2}{*}{0.05} & 3.030 & 0.782 & 0.028 & -0.057 & \multirow{2}{*}{-0.029} & \multirow{2}{*}{-0.001} \\
\hline & $(7.852)^{\star \star \star}$ & $(30.394)^{\star \star \star}$ & $(1.993)^{\star \star}$ & $(-3.091)^{\star \star \star}$ & & \\
\hline \multirow{2}{*}{0.10} & 2.789 & 0.801 & 0.050 & -0.083 & \multirow{2}{*}{-0.032} & \multirow{2}{*}{0.018} \\
\hline & $(7.077)^{\star \star \star}$ & $(30.697)^{\star \star \star}$ & $(3.838)^{\star \star \star}$ & $(-4.236)^{\star \star \star}$ & & \\
\hline \multirow{2}{*}{0.15} & 2.734 & 0.807 & 0.048 & -0.079 & \multirow{2}{*}{-0.031} & \multirow{2}{*}{0.017} \\
\hline & $(7.901)^{\star \star \star}$ & $(35.064)^{\star * *}$ & $(4.959)^{\star \star \star}$ & $(-4.871)^{\star \star \star}$ & & \\
\hline \multirow{2}{*}{0.20} & 2.564 & 0.821 & 0.051 & -0.081 & \multirow{2}{*}{-0.030} & \multirow{2}{*}{0.021} \\
\hline & $(7.332)^{\star \star \star}$ & $(35.337)^{\star \star \star}$ & $(5.154)^{\star \star \star}$ & $(-5.501)^{\star \star \star}$ & & \\
\hline \multirow{2}{*}{0.25} & 2.501 & 0.826 & 0.061 & -0.090 & \multirow{2}{*}{-0.030} & \multirow{2}{*}{0.031} \\
\hline & $(9.287)^{\star \star \star}$ & $(46.323)^{\star \star \star}$ & $(5.649)^{\star \star \star}$ & $(-5.643)^{\star \star \star}$ & & \\
\hline \multirow{2}{*}{0.30} & 2.515 & 0.826 & 0.071 & -0.110 & \multirow{2}{*}{-0.038} & \multirow{2}{*}{0.033} \\
\hline & $(10.725)^{\star \star \star}$ & $(53.321)^{\star \star \star}$ & $(7.598)^{\star \star \star}$ & $(-7.843)^{\star \star \star}$ & & \\
\hline
\end{tabular}


Table 7 (cont.). Quantile regression estimates of volume-signed return correlation for TAIEX in the partly-eliminated period

\begin{tabular}{|c|c|c|c|c|c|c|}
\hline Quantile & $c$ & a & $b$ & y & $b+\gamma$ & $b+(b+\gamma)$ \\
\hline \multicolumn{7}{|c|}{ Panel A. Share volume vs. returns } \\
\hline \multirow{2}{*}{0.35} & 2.514 & 0.828 & 0.075 & -0.115 & \multirow{2}{*}{-0.041} & \multirow{2}{*}{0.034} \\
\hline & $(11.003)^{\star \star \star}$ & $(54.401)^{\star \star \star}$ & $(8.097)^{\star \star \star}$ & $(-8.351)^{\star \star \star}$ & & \\
\hline \multirow{2}{*}{0.40} & 2.526 & 0.828 & 0.082 & -0.125 & \multirow{2}{*}{-0.043} & \multirow{2}{*}{0.039} \\
\hline & $(12.745)^{\star \star \star}$ & $(62.973)^{\star \star \star}$ & $(8.847)^{\star \star \star}$ & $(-9.466)^{\star \star \star}$ & & \\
\hline \multirow{2}{*}{0.45} & 2.566 & 0.826 & 0.088 & -0.133 & \multirow{2}{*}{-0.045} & \multirow{2}{*}{0.043} \\
\hline & $(13.186)^{\star \star \star}$ & $(64.070)^{\star \star \star}$ & $(9.112)^{\star \star \star}$ & $(-10.653)^{\star \star *}$ & & \\
\hline \multirow{2}{*}{0.50} & 2.623 & 0.823 & 0.092 & -0.137 & \multirow{2}{*}{-0.044} & \multirow{2}{*}{0.048} \\
\hline & $(13.741)^{\star \star \star}$ & $(65.411)^{\star \star \star}$ & $(10.848)^{\star * *}$ & $(-12.115)^{\star \star \star}$ & & \\
\hline \multirow{2}{*}{0.55} & 2.599 & 0.826 & 0.097 & -0.141 & \multirow{2}{*}{-0.044} & \multirow{2}{*}{0.054} \\
\hline & $(12.532)^{\star \star \star}$ & $(59.862)^{\star \star \star}$ & $(12.124)^{\star \star \star}$ & $(-11.945)^{\star \star \star}$ & & \\
\hline \multirow{2}{*}{0.60} & 2.335 & 0.844 & 0.099 & -0.140 & \multirow{2}{*}{-0.041} & 0057 \\
\hline & $(11.751)^{\star \star \star}$ & $(63.672)^{\star \star \star}$ & $(15.174)^{\star \star \star}$ & $(-14.227)^{\star \star \star}$ & & 0.051 \\
\hline 065 & 2.308 & 0.848 & 0.098 & -0.138 & $0 \cap 30$ & 0050 \\
\hline 0.05 & $(9.831)^{\star * \star}$ & $(54.468)^{\star \star \star}$ & $(13.205)^{\star * \star}$ & $(-11.487)^{\star \star \star}$ & -0.039 & 0.059 \\
\hline & 2.244 & 0.853 & 0.093 & -0.137 & 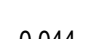 & \\
\hline 0.10 & $(9.957)^{\star \star \star}$ & $(57.081)^{\star \star \star}$ & $(12.111)^{\star \star \star}$ & $(-11.507)^{\star \star \star}$ & -0.044 & 0.049 \\
\hline 075 & 2.238 & 0.855 & 0.091 & -0.133 & 012 & 040 \\
\hline 0.10 & $(7.962)^{\star \star \star}$ & $(46.132)^{\star \star \star}$ & $(9.473)^{\star \star \star}$ & $(-9.561)^{\star \star \star}$ & -0.043 & 0.048 \\
\hline & 2.275 & 0.854 & 0.098 & -0.147 & & \\
\hline 0.00 & $(10.490)^{\star \star \star}$ & $(60.085)^{\star \star \star}$ & $(12.558)^{\star \star \star}$ & $(-11.427)^{\star * \star}$ & -0.049 & 0.040 \\
\hline 085 & 2.317 & 0.852 & 0.096 & -0.148 & 0052 & $\cap \Omega M A$ \\
\hline 0.00 & $(10.145)^{\star \star \star}$ & $(56.596)^{\star \star \star}$ & $(11.672)^{\star \star \star}$ & $(-10.885)^{* \star \star}$ & -0.052 & 0.044 \\
\hline 促 & 2.655 & 0.832 & 0.104 & -0.162 & ב50 & ב \\
\hline 0.90 & $(9.807)^{\star \star \star}$ & $(46.866)^{\star \star \star}$ & $(8.535)^{\star \star \star}$ & $(-8.875)^{\star \star \star}$ & -0.051 & $0.04 I$ \\
\hline & 2.907 & 0.818 & 0.110 & -0.174 & 0 & $0 \Omega$ \\
\hline 0.95 & $(7.879)^{\star \star \star}$ & $(33.445)^{\star \star \star}$ & $(12.161)^{\star \star \star}$ & $(-13.137)^{\star \star \star}$ & -0.066 & 0.046 \\
\hline 099 & 2.407 & 0.859 & 0.092 & -0.132 & $=\cap \Omega 40$ & 0052 \\
\hline 0.99 & $(3.942)^{\star \star \star}$ & $(21.432)^{\star \star \star}$ & $(5.741)^{\star \star \star}$ & $(-6.339)^{\star \star \star}$ & -0.040 & 0.032 \\
\hline Panel B. Doll & vs. returns & & & & & \\
\hline$\cap 01$ & 2.950 & 0.816 & 0.041 & -0.078 & 0027 & $0 \cap 0 \Omega$ \\
\hline 0.01 & $(3.813)^{\star \star \star}$ & $(19.453)^{\star \star \star}$ & $(1.905)^{\star}$ & $(-3.039)^{\star \star \star}$ & -0.031 & 0.004 \\
\hline 005 & 2.520 & 0.846 & 0.039 & -0.065 & 0026 & 0012 \\
\hline 0.00 & $(4.192)^{\star \star \star}$ & $(25.799)^{\star \star \star}$ & $(2.349)^{\star *}$ & $(-2.664)^{\star \star \star}$ & -0.026 & 0.013 \\
\hline 010 & 2.885 & 0.829 & 0.051 & -0.076 & 0025 & 0026 \\
\hline 0.10 & $(6.174)^{\star \star \star}$ & $(32.628)^{\star \star \star}$ & $(3.765)^{\star \star \star}$ & $(-3.689)^{\star \star \star}$ & -0.025 & 0.026 \\
\hline 015 & 2.627 & 0.846 & 0.056 & -0.086 & $=0 \cap 31$ & $0 \Omega 05$ \\
\hline 0.10 & $(5.351)^{\star \star \star}$ & $(31.632)^{\star \star \star}$ & $(3.913)^{\star \star \star}$ & $(-4.309)^{\star \star \star}$ & 1 & $0.0<0$ \\
\hline מכ? & 2.799 & 0.838 & 0.075 & -0.108 & 0033 & 0040 \\
\hline $0 . \angle 0$ & $(9.985)^{\star \star *}$ & $(54.937)^{\star * \star}$ & $(7.296)^{\star \star \star}$ & $(-6.859)^{\star \star \star}$ & -0.000 & 0.042 \\
\hline 025 & 2.975 & 0.830 & 0.076 & -0.110 & $=0034$ & $\cap 042$ \\
\hline 0.20 & $(8.459)^{\star \star \star}$ & $(43.607)^{\star \star \star}$ & $(8.115)^{\star \star \star}$ & $(-6.671)^{\star \star \star}$ & -0.034 & 0.042 \\
\hline 030 & 2.998 & 0.830 & 0.077 & -0.116 & $0 \cap 30$ & $\cap \cap 30$ \\
\hline 0.30 & $(8.611)^{\star \star *}$ & $(43.850)^{\star \star \star}$ & $(6.662)^{\star \star \star}$ & $(-7.418)^{\star \star \star}$ & -0.035 & 0.039 \\
\hline 035 & 2.892 & 0.837 & 0.087 & -0.125 & 0037 & 0050 \\
\hline 0.35 & $(10.949)^{\star \star \star}$ & $(58.214)^{\star \star \star}$ & $(7.143)^{\star \star \star}$ & $(-7.846)^{\star \star \star}$ & -0.031 & 0.050 \\
\hline 040 & 2.926 & 0.836 & 0.097 & -0.136 & $0 \cap 30$ & 0050 \\
\hline 0.40 & $(11.481)^{\star \star \star}$ & $(60.215)^{\star \star \star}$ & $(8.562)^{\star \star \star}$ & $(-9.583)^{\star \star *}$ & -0.039 & 0.058 \\
\hline 0.45 & 2.973 & 0.834 & 0.104 & -0.141 & $-0,037$ & 0067 \\
\hline 0.40 & $(12.908)^{\star \star \star}$ & $(66.476)^{\star \star \star}$ & $(10.350)^{\star * \star}$ & $(-10.562)^{* \star *}$ & & \\
\hline 050 & 3.110 & 0.828 & 0.105 & -0.140 & -0035 & 0069 \\
\hline 0.50 & $(14.974)^{\star \star \star}$ & $(73.661)^{\star \star \star}$ & $(11.460)^{\star \star \star}$ & $(-11.129)^{\star \star \star}$ & -0.035 & 0.069 \\
\hline 0.55 & 3.273 & 0.820 & 0.109 & -0.149 & $-0 \Omega 40$ & 070 \\
\hline 0.00 & $(15.061)^{\star * *}$ & $(69.778)^{\star * *}$ & $(12.751)^{\star \star \star}$ & $(-12.694)^{\star \star \star}$ & -0.040 & 0.010 \\
\hline
\end{tabular}


Table 7 (cont.). Quantile regression estimates of volume-signed return correlation for TAIEX in the partly-eliminated period

\begin{tabular}{|c|c|c|c|c|c|c|}
\hline Quantile & $c$ & $a$ & $b$ & y & $b+y$ & $b+(b+\gamma)$ \\
\hline \multicolumn{7}{|c|}{ Panel B. Dollar volume vs. returns } \\
\hline \multirow{2}{*}{0.60} & 3.152 & 0.828 & 0.111 & -0.149 & \multirow{2}{*}{-0.039} & \multirow{2}{*}{0.072} \\
\hline & $(13.007)^{\star \star \star}$ & $(62.748)^{\star \star \star *}$ & $(15.586)^{\star \star \star}$ & $(-13.852)^{\star \star \star}$ & & \\
\hline \multirow{2}{*}{0.65} & 2.988 & 0.838 & 0.106 & -0.149 & \multirow{2}{*}{-0.044} & \multirow{2}{*}{0.062} \\
\hline & $(8.966)^{\star \star \star}$ & $(45.939)^{\star \star \star}$ & $(15.430)^{\star * *}$ & $(-12.512)^{\star \star \star}$ & & \\
\hline \multirow{2}{*}{0.70} & 2.967 & 0.840 & 0.102 & -0.144 & \multirow{2}{*}{-0.042} & \multirow{2}{*}{0.060} \\
\hline & $(10.248)^{\star \star \star}$ & $(53.399)^{\star \star \star}$ & $(12.096)^{\star \star \star}$ & $(-11.300)^{\star \star \star}$ & & \\
\hline \multirow{2}{*}{0.75} & 3.069 & 0.836 & 0.108 & -0.150 & \multirow{2}{*}{-0.042} & \multirow{2}{*}{0.066} \\
\hline & $(12.516)^{\star \star \star}$ & $(62.636)^{\star \star \star}$ & $(12.302)^{\star \star \star}$ & $(-10.430)^{\star \star \star}$ & & \\
\hline \multirow{2}{*}{0.80} & 2.930 & 0.845 & 0.109 & -0.158 & \multirow{2}{*}{-0.049} & \multirow{2}{*}{0.059} \\
\hline & $(11.018)^{\star \star \star}$ & $(58.678)^{\star \star \star}$ & $(10.779)^{\star \star \star}$ & $(-10.152)^{\star \star \star}$ & & \\
\hline \multirow{2}{*}{0.85} & 3.242 & 0.829 & 0.118 & -0.173 & \multirow{2}{*}{-0.055} & \multirow{2}{*}{0.062} \\
\hline & $(13.603)^{\star \star \star}$ & $(64.233)^{\star \star \star}$ & $(12.267)^{\star \star \star}$ & $(-12.921)^{\star \star \star}$ & & \\
\hline \multirow{2}{*}{0.90} & 3.417 & 0.821 & 0.120 & -0.174 & \multirow{2}{*}{-0.054} & \multirow{2}{*}{0.066} \\
\hline & $(10.554)^{\star \star \star}$ & $(47.146)^{\star \star \star}$ & $(11.363)^{\star \star \star}$ & $(-10.844)^{\star \star \star}$ & & \\
\hline \multirow{2}{*}{0.95} & 3.918 & 0.797 & 0.128 & -0.185 & \multirow{2}{*}{-0.057} & \multirow{2}{*}{0.070} \\
\hline & $(7.033)^{\star \star \star}$ & $(26.382)^{\star \star \star}$ & $(8.570)^{\star \star \star}$ & $(-9.222)^{\star \star \star}$ & & \\
\hline \multirow{2}{*}{0.99} & 3.965 & 0.803 & 0.088 & -0.114 & \multirow{2}{*}{-0.026} & \multirow{2}{*}{0.062} \\
\hline & $(7.678)^{\star \star \star}$ & $(28.992)^{\star \star \star}$ & $(5.044)^{\star \star \star}$ & $(-4.579)^{\star \star \star}$ & & \\
\hline
\end{tabular}

Notes: Those in parentheses are $t$-statistics for the intercept and the coefficients estimates. $*, * *$ and $* * *$ indicates significance at the $10 \%, 5 \%$ and $1 \%$ levels, respectively.

Table 8. Quantile regression estimates of volume-signed return correlation for TAIEX in the entirely-eliminated period

\begin{tabular}{|c|c|c|c|c|c|c|}
\hline Quantile & c & a & $b$ & y & $b+y$ & $b+(b+y)$ \\
\hline \multicolumn{7}{|c|}{ Panel A. Share volume vs. returns } \\
\hline \multirow{2}{*}{0.01} & 4.053 & 0.721 & 0.032 & -0.024 & \multirow{2}{*}{0.008} & \multirow{2}{*}{0.039} \\
\hline & $(2.605)^{\star \star \star}$ & $(7.081)^{\star \star \star}$ & $(0.441)$ & $(-0.221)$ & & \\
\hline \multirow{2}{*}{0.05} & 3.173 & 0.781 & 0.070 & -0.116 & \multirow{2}{*}{-0.046} & \multirow{2}{*}{0.025} \\
\hline & $(3.395)^{\star \star \star}$ & $(12.892)^{\star \star \star}$ & $(1.233)$ & $(-1.378)$ & & \\
\hline \multirow{2}{*}{0.10} & 3.298 & 0.775 & 0.090 & -0.147 & \multirow{2}{*}{-0.057} & \multirow{2}{*}{0.032} \\
\hline & $(4.598)^{* * *}$ & $(16.690)^{* * *}$ & $(2.591)^{\star \star \star}$ & $(-2.697)^{\star * *}$ & & \\
\hline \multirow{2}{*}{0.15} & 2.977 & 0.796 & 0.115 & -0.204 & \multirow{2}{*}{-0.089} & \multirow{2}{*}{0.026} \\
\hline & $(4.850)^{\star \star \star}$ & $(20.132)^{\star \star \star}$ & $(3.749)^{\star \star \star}$ & $(-3.904)^{\star \star \star}$ & & \\
\hline \multirow{2}{*}{0.20} & 3.486 & 0.764 & 0.133 & -0.229 & \multirow{2}{*}{-0.095} & \multirow{2}{*}{0.038} \\
\hline & $(5.466)^{\star * \star}$ & $(18.589)^{* \star *}$ & $(5.247)^{\star \star \star}$ & $(-5.350)^{\star * *}$ & & \\
\hline \multirow{2}{*}{0.25} & 3.657 & 0.754 & 0.139 & -0.231 & \multirow{2}{*}{-0.093} & \multirow{2}{*}{0.046} \\
\hline & $(6.009)^{\star * \star}$ & $(19.193)^{\star * *}$ & $(5.890)^{\star \star \star}$ & $(-6.307)^{\star * *}$ & & \\
\hline \multirow{2}{*}{0.30} & 3.566 & 0.761 & 0.139 & -0.237 & \multirow{2}{*}{-0.098} & \multirow{2}{*}{0.041} \\
\hline & $(6.784)^{\star \star \star *}$ & $(22.374)^{\star * *}$ & $(6.181)^{\star \star \star}$ & $(-7.280)^{\star * *}$ & & \\
\hline \multirow{2}{*}{0.35} & 3.698 & 0.753 & 0.139 & -0.231 & \multirow{2}{*}{-0.093} & \multirow{2}{*}{0.046} \\
\hline & $(7.090)^{\star * \star}$ & $(22.211)^{\star \star \star}$ & $(6.204)^{\star \star \star}$ & $(-7.421)^{\star \star \star \star}$ & & \\
\hline \multirow{2}{*}{0.40} & 3.621 & 0.759 & 0.146 & -0.236 & \multirow{2}{*}{-0.090} & \multirow{2}{*}{0.056} \\
\hline & $(6.597)^{\star \star \star}$ & $(21.164)^{\star * *}$ & $(7.403)^{\star \star *}$ & $(-8.429)^{\star * *}$ & & \\
\hline \multirow{2}{*}{0.45} & 3.598 & 0.762 & 0.138 & -0.221 & \multirow{2}{*}{-0.083} & \multirow{2}{*}{0.056} \\
\hline & $(7.464)^{\star \star \star}$ & $(24.176)^{\star \star \star}$ & $(8.460)^{\star \star \star}$ & $(-8.895)^{\star \star \star}$ & & \\
\hline 050 & 3.260 & 0.785 & 0.136 & -0.212 & -0077 & 0060 \\
\hline 0.00 & $(6.742)^{\star \star \star}$ & $(24.796)^{\star \star \star}$ & $(9.793)^{\star \star \star}$ & $(-9.054)^{* * *}$ & -0.010 & .000 \\
\hline 055 & 3.353 & 0.779 & 0.132 & -0.215 & 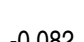 & 0000 \\
\hline 0.55 & $(6.561)^{\star \star \star}$ & $(23.347)^{\star * *}$ & $(9.869)^{\star \star \star}$ & $(-9.313)^{\star * *}$ & -0.082 & 0.050 \\
\hline 060 & 3.180 & 0.791 & 0.133 & -0.209 & -0070 & 0057 \\
\hline 0.00 & $(5.456)^{\star \star \star}$ & $(20.798)^{\star \star \star \star}$ & $(8.466)^{\star \star \star}$ & $(-7.886)^{\star \star \star}$ & -0.010 & 0.051 \\
\hline 065 & 3.131 & 0.796 & 0.130 & -0.201 & 0070 & 000 \\
\hline 0.05 & $(5.446)^{\star \star \star}$ & $(21.294)^{\star \star \star}$ & $(8.042)^{\star \star \star}$ & $(-7.300)^{\star \star \star}$ & -0.010 & 0.000 \\
\hline
\end{tabular}


Table 8 (cont.). Quantile regression estimates of volume-signed return correlation for TAIEX in the entirely-eliminated period

\begin{tabular}{|c|c|c|c|c|c|c|}
\hline Quantile & $c$ & a & $b$ & V & $b+\gamma$ & $b+(b+v)$ \\
\hline \multicolumn{7}{|c|}{ Panel A. Share volume vs. returns } \\
\hline \multirow{2}{*}{0.70} & 3.028 & 0.803 & 0.140 & -0.223 & \multirow{2}{*}{-0.083} & \multirow{2}{*}{0.057} \\
\hline & $(5.017)^{\star \star \star}$ & $(20.537)^{\star \star \star}$ & $(8.238)^{\star \star \star}$ & $(-7.666)^{\star \star \star}$ & & \\
\hline \multirow{2}{*}{0.75} & 3.206 & 0.793 & 0.126 & -0.200 & \multirow{2}{*}{-0.075} & \multirow{2}{*}{0.051} \\
\hline & $(5.651)^{\star \star \star}$ & $(21.463)^{\star \star \star}$ & $(8.452)^{\star \star \star}$ & $(-7.404)^{\star \star \star}$ & & \\
\hline \multirow{2}{*}{0.80} & 2.909 & 0.813 & 0.121 & -0.194 & \multirow{2}{*}{-0.073} & \multirow{2}{*}{0.048} \\
\hline & $(4.475)^{\star \star \star}$ & $(19.185)^{\star \star \star}$ & $(7.117)^{\star \star \star}$ & $(-6.865)^{\star \star \star}$ & & \\
\hline \multirow{2}{*}{0.85} & 3.219 & 0.794 & 0.122 & -0.202 & \multirow{2}{*}{-0.080} & \multirow{2}{*}{0.042} \\
\hline & $(3.503)^{\star \star \star}$ & $(13.254)^{\star \star \star}$ & $(5.870)^{\star \star \star}$ & $(-6.124)^{\star \star \star}$ & & \\
\hline \multirow{2}{*}{0.90} & 2.503 & 0.842 & 0.118 & -0.192 & \multirow{2}{*}{-0.074} & \multirow{2}{*}{0.043} \\
\hline & $(1.948)^{*}$ & $(10.073)^{\star \star \star}$ & $(4.740)^{\star \star \star}$ & $(-5.334)^{\star \star \star}$ & & \\
\hline \multirow{2}{*}{0.95} & 2.711 & 0.831 & 0.123 & -0.196 & \multirow{2}{*}{-0.073} & 0050 \\
\hline & $(1.840)^{*}$ & $(8.684)^{\star \star \star}$ & $(6.609)^{\star \star \star}$ & $(-6.822)^{\star \star \star}$ & & 0.050 \\
\hline & 3.794 & 0.770 & 0.121 & -0.137 & & \\
\hline 0.99 & (1.501) & $(4.687)^{\star \star \star}$ & $(1.332)$ & $(-1.103)$ & -0.010 & 0.100 \\
\hline Panel B. Doll & vs. returns & & & & & \\
\hline 001 & 3.422 & 0.798 & -0.061 & 0.147 & ח & 0025 \\
\hline 0.01 & $(0.866)$ & $(3.702)^{\star \star \star}$ & $(-0.463)$ & $(0.613)$ & 0.000 & $0.0<0$ \\
\hline 005 & 6.967 & 0.606 & 0.108 & -0.209 & 0101 & $\cap \cap \cap 7$ \\
\hline 0.00 & $(3.904)^{\star \star \star}$ & $(6.261)^{\star \star *}$ & $(1.150)$ & $(-1.670)^{\star}$ & -0.101 & 0.001 \\
\hline 010 & 6.066 & 0.656 & 0.167 & -0.296 & 0120 & 0030 \\
\hline 0.10 & $(6.803)^{\star \star \star}$ & $(13.527)^{\star \star \star}$ & $(3.262)^{\star \star \star}$ & $(-4.280)^{\star \star \star}$ & $-0.1<y$ & 0.039 \\
\hline 015 & 6.364 & 0.642 & 0.154 & -0.271 & 0117 & 0027 \\
\hline 0.15 & $(6.223)^{\star \star \star}$ & $(11.533)^{\star \star \star}$ & $(6.029)^{\star \star \star}$ & $(-6.915)^{\star \star \star}$ & -0.111 & 0.031 \\
\hline חמת ח & 6.453 & 0.638 & 0.139 & -0.243 & 0105 & $0 \Omega 21$ \\
\hline $0 . \angle 0$ & $(6.211)^{\star \star \star}$ & $(11.266)^{\star \star \star}$ & $(6.261)^{\star * *}$ & $(-7.127)^{\star \star \star}$ & -0.100 & 0.004 \\
\hline & 6.228 & 0.652 & 0.163 & -0.263 & & \\
\hline 0.25 & $(5.457)^{\star * *}$ & $(10.471)^{\star * *}$ & $(7.124)^{\star \star *}$ & $(-6.625)^{\star * *}$ & -0.100 & 0.064 \\
\hline ח 30 & 5.836 & 0.675 & 0.142 & -0.234 & ?०० & 0050 \\
\hline 0.00 & $(5.633)^{\star \star \star}$ & $(11.966)^{\star \star *}$ & $(6.240)^{\star \star \star}$ & $(-5.652)^{\star \star \star}$ & -0.096 & 0.000 \\
\hline 035 & 6.212 & 0.655 & 0.130 & -0.222 & $\cap 09 ?$ & 0030 \\
\hline 0.30 & $(6.786)^{\star \star \star}$ & $(13.123)^{\star \star \star}$ & $(6.009)^{\star \star \star}$ & $(-6.036)^{\star \star \star}$ & -0.092 & 0.039 \\
\hline 040 & 5.994 & 0.668 & 0.129 & -0.214 & -0085 & 0045 \\
\hline 0.40 & $(7.029)^{\star \star \star}$ & $(14.358)^{\star \star \star}$ & $(5.898)^{\star \star \star}$ & $(-6.427)^{\star * \star}$ & & 0.045 \\
\hline 015 & 6.537 & 0.639 & 0.125 & -0.206 & ค م01 & 0044 \\
\hline 0.45 & $(7.062)^{\star \star \star}$ & $(12.695)^{\star \star \star}$ & $(5.258)^{\star \star \star}$ & $(-5.857)^{\star \star \star}$ & -0.081 & 0.044 \\
\hline 050 & 6.510 & 0.642 & 0.119 & -0.204 & -0085 & 0033 \\
\hline 0.00 & $(6.744)^{\star \star \star}$ & $(12.220)^{\star \star \star}$ & $(4.851)^{\star \star \star}$ & $(-5.541)^{\star \star \star}$ & -0.000 & 0.000 \\
\hline 055 & 6.573 & 0.639 & 0.138 & -0.229 & $0 \cap 091$ & 0047 \\
\hline 0.00 & $(6.406)^{\star * \star}$ & $(11.416)^{\star \star \star}$ & $(5.813)^{\star \star \star}$ & $(-6.286)^{\star * \star}$ & -0.091 & 0.047 \\
\hline 060 & 6.176 & 0.661 & 0.141 & -0.224 & ?חמח & 0050 \\
\hline 0.00 & $(5.807)^{\star \star \star}$ & $(11.371)^{\star \star \star}$ & $(6.347)^{\star \star \star}$ & $(-5.894)^{\star \star \star}$ & -0.082 & 0.059 \\
\hline 065 & 5.938 & 0.675 & 0.142 & -0.227 & 0085 & 0057 \\
\hline 0.05 & $(5.708)^{\star \star \star}$ & $(11.875)^{\star \star \star}$ & $(6.550)^{\star \star \star}$ & $(-5.795)^{\star \star \star}$ & -0.085 & 0.051 \\
\hline O 70 & 5.403 & 0.705 & 0.141 & -0.231 & $0 \cap 80$ & 0052 \\
\hline 0.10 & $(4.714)^{\star \star \star}$ & $(11.293)^{\star \star \star}$ & $(6.336)^{\star \star \star}$ & $(-5.748)^{\star \star \star}$ & -0.089 & 0.052 \\
\hline 075 & 5.776 & 0.685 & 0.143 & -0.235 & 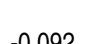 & 0051 \\
\hline 0.15 & $(4.644)^{\star * \star}$ & $(10.131)^{\star \star \star}$ & $(5.904)^{\star \star \star}$ & $(-5.628)^{\star * *}$ & -0.092 & 0.051 \\
\hline 080 & 6.378 & 0.654 & 0.139 & -0.236 & $-0,098$ & 0,041 \\
\hline 0.80 & $(5.081)^{\star \star \star *}$ & $(9.554)^{\star * \star}$ & $(5.095)^{\star \star \star}$ & $(-5.458)^{\star \star \star}$ & & \\
\hline 085 & 6.372 & 0.655 & 0.160 & -0.278 & -0118 & 0,041 \\
\hline 0.80 & $(5.026)^{\star \star \star}$ & $(9.445)^{\star \star \star}$ & $(6.362)^{\star \star \star}$ & $(-6.955)^{\star \star *}$ & -0.118 & 0.041 \\
\hline م00 & 5.933 & 0.680 & 0.159 & -0.275 & 0110 & $0 \cap 12$ \\
\hline 0.90 & $(4.040)^{\star * \star}$ & $(8.453)^{\star \star \star}$ & $(6.573)^{\star \star \star}$ & $(-7.225)^{\star \star \star}$ & -0.116 & 0.043 \\
\hline
\end{tabular}


Table 8 (cont.). Quantile regression estimates of volume-signed return correlation for TAIEX in the entirely-eliminated period

\begin{tabular}{|c|c|c|c|c|c|c|}
\hline Quantile & $c$ & $a$ & $b$ & y & $b+y$ & $b+(b+\gamma)$ \\
\hline \multicolumn{7}{|c|}{ Panel B. Dollar volume vs. returns } \\
\hline \multirow{2}{*}{0.95} & 5.088 & 0.730 & 0.112 & -0.218 & \multirow{2}{*}{-0.106} & \multirow{2}{*}{0.005} \\
\hline & $(2.114)^{\star \star}$ & $(5.535)^{\star \star \star}$ & $(1.996)^{\star \star}$ & $(-3.114)^{\star \star \star}$ & & \\
\hline \multirow{2}{*}{0.99} & 8.520 & 0.550 & 0.129 & -0.177 & \multirow{2}{*}{-0.047} & \multirow{2}{*}{0.082} \\
\hline & $(2.490)^{\star *}$ & $(2.962)^{\star \star \star}$ & $(1.713)^{\star}$ & $(-1.810)^{*}$ & & \\
\hline
\end{tabular}

Notes: Those in parentheses are $t$-statistics for the intercept and the coefficients estimates. ${ }^{*}, * *$ and $* * *$ indicates significance at the $10 \%, 5 \%$ and $1 \%$ levels, respectively.

Autocorrelation of share volume

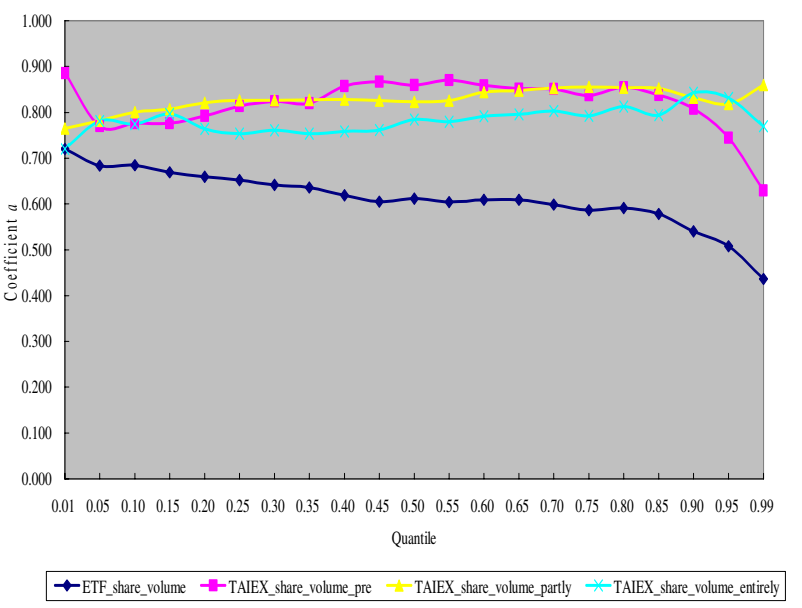

Autocorrelation of dollar volume

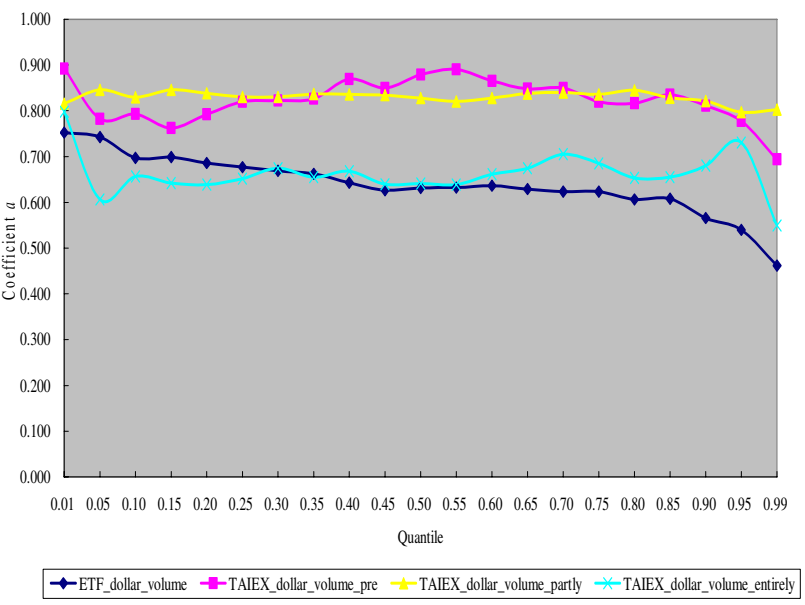

Fig. 3. Autocorrelations of volume series

Share volume vs. returns

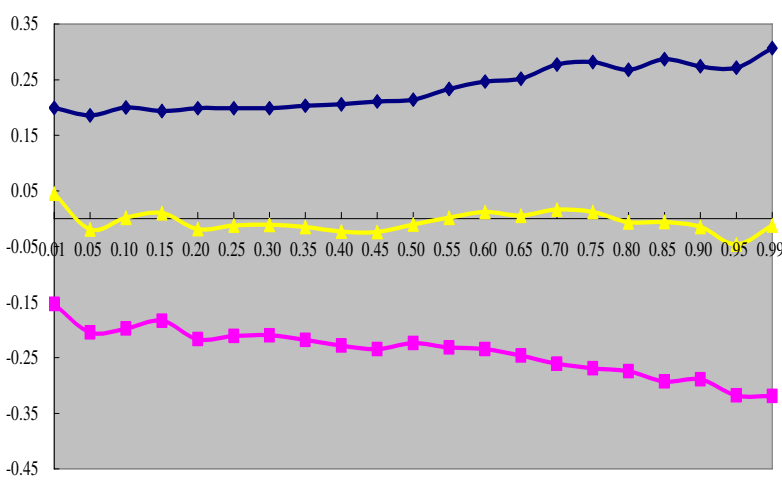

Quantile

$\rightarrow$ non-negative $\rightarrow$ negative - asymmetric effect
Dollar volume vs. returns

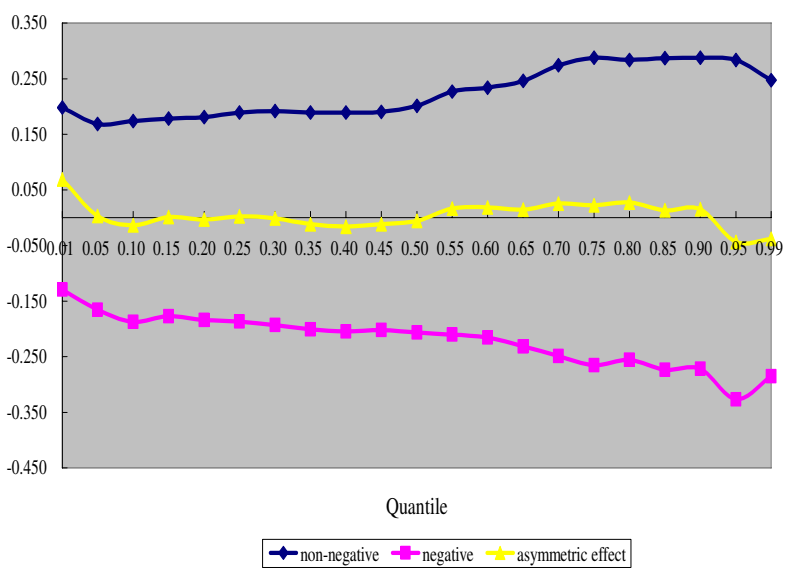

Fig. 4. Quantile regression estimates of volume-signed return correlation for Taiwan 50 ETF in the full-sample period 

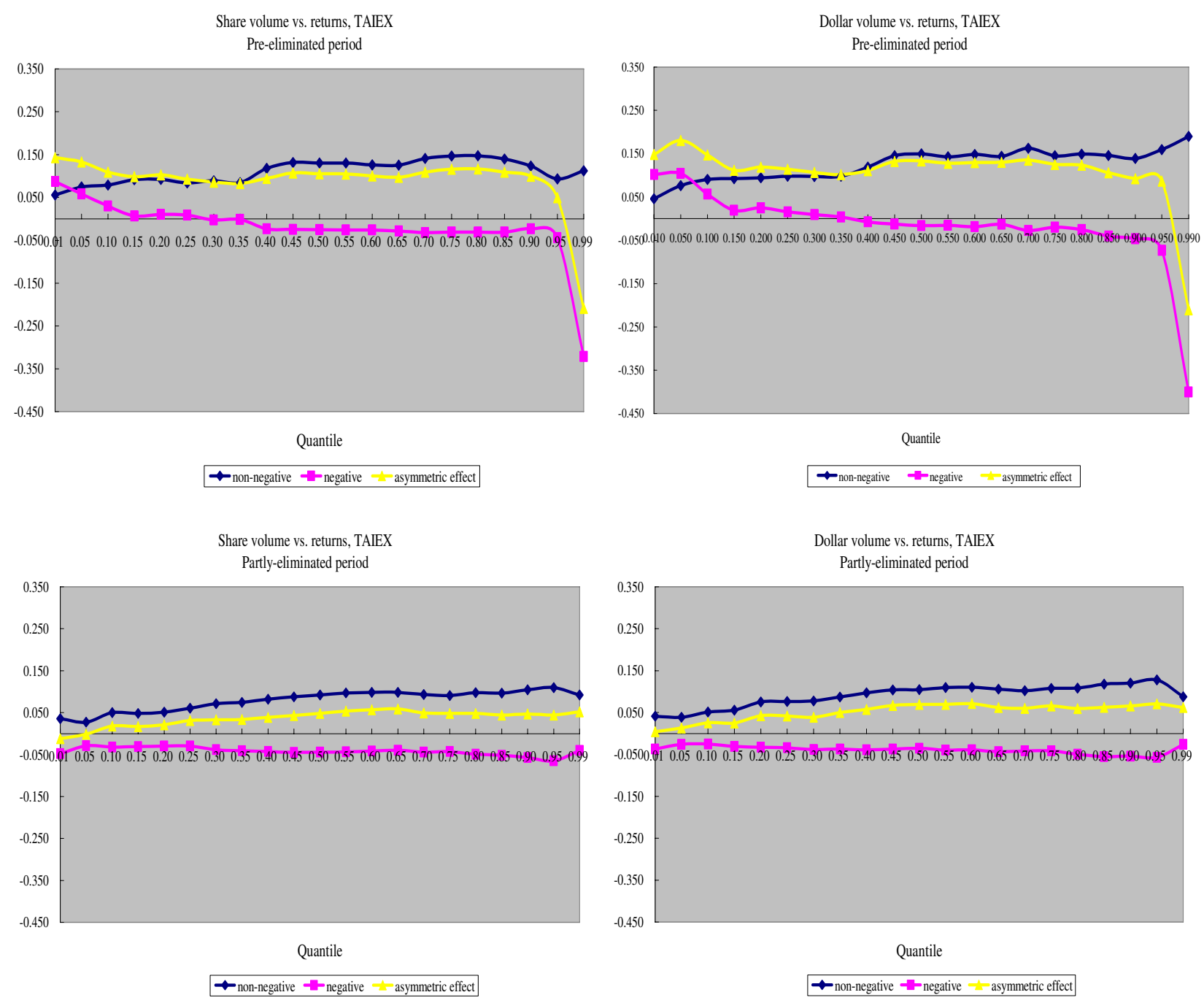

Share volume vs. returns, TAIEX

Entirely-eliminated period

Dollar volume vs. returns, TAIEX Entirely-eliminated period
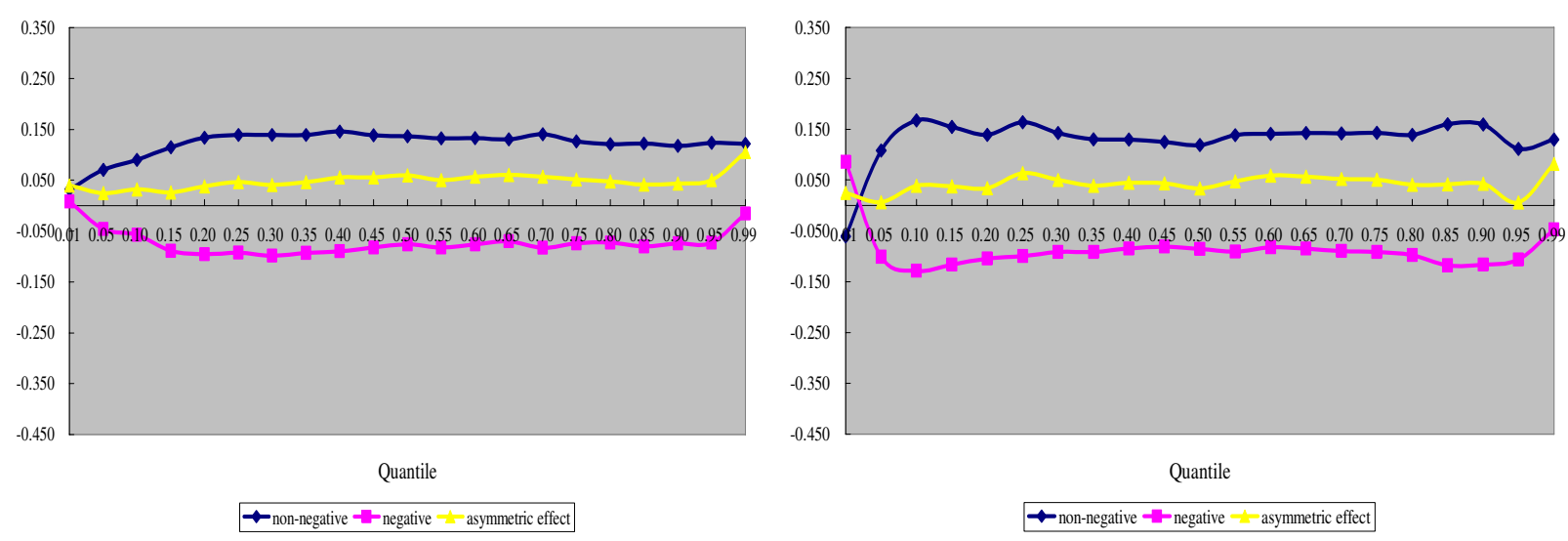

Fig. 5. Quantile regression estimates of volume-signed return correlation for TAIEX in three sub periods

\section{Conclusion}

It has been intensively argued over the ground for the strong empirical link between volume and signed returns in various financial markets. While previous studies on volume-signed return relationship generally focus on one single financial instrument and hence obtain inferences that are limited or unilateral, this study simultaneously examines the ETF and equity's volume-return connections so as to acquire crossproduct evidence to objectively evaluate various competing hypotheses for explaining the volumereturn phenomenon. The differences in the transaction costs and in the applicability to the short-sale restriction between Taiwan's ETFs and equities provide an appropriate framework to test the various hypotheses for volume-return relationship. 
Three classified hypotheses are examined in this study to explain volume-signed return relationship. Firstly, the costly short-sale hypothesis considers the short-sale restriction and asymmetric transaction costs on long and short trading to be the source of the asymmetric volume-return relationship in most equity markets and hence predicts an obviously positive asymmetric volume-return relationship in Taiwan's equities and a less positive asymmetric one in Taiwan's ETFs. This hypothesis also predicts that the asymmetry in equities may diminish with the gradual elimination of the short-sale restriction. Secondly, the MDH considers volume and returns to be commonly driven by an exogenous mixing variable and hence predicts a significant contemporaneous volume-signed return correlation for both the ETF and equity index. Thirdly, the trader heterogeneity hypothesis considers uninformed traders to be the source of volumereturn correlations and suggests that a price decline adds to greater dispersion of beliefs or the underlying information signal, resulting in larger abnormal volume on negative returns and hence predicts a likely negative asymmetric volume-return relationship in Taiwan's ETFs.

The empirical results show that volume strongly correlates to either direction of returns for both the ETF and the equity index, concluding that the MDH cannot be rejected. The strong contemporaneous volume-return correlations are also consistent with the arguments of the later information models, which regard the cotemporaneous relationship as a result of the uninformed traders' simultaneous reaction to the changes in volume and returns. For both the ETF and the equity index in the preeliminated period, the later information models can further explain the upward trend in the correlation magnitude with the grow of volume quantiles. The evidences that the magnitude of the correlations of volume associated with either direction of returns is stronger for the ETF than for TAIEX and that the magnitude of these correlations for TAIEX grows with the gradual elimination of the short-sale uptick rule indicate that the costly short-sale hypothesis cannot be rejected either.

Finally, significant asymmetries are found in the contemporaneous volume-return correlations for the ETF and the equity index in which the ETF display a mixed, negative or positive, asymmetry and the equity index exhibits primarily a positive asymmetry. The evidence that the contemporaneous volume-return correlations for TAIEX are positively asymmetric and decline with the elimination of the short-sale restriction indicates that the costly short-sale hypothesis cannot be rejected. The part of a less positive asymmetric volume-return relationship in the ETF is also consistent with what the costly short-sale hypothesis predicts, whereas the part of a slightly negative asymmetric volume-return relationship in the ETF is consistent with the prediction of the later information models. Hence, this study concludes that not a single hypothesis can be a universal explanation for the asymmetric volume-return relationship. Which hypothesis may explain the asymmetrical volume-signed return relationship depends on whether the short-sale restriction is present. The costly short-sale hypothesis can explain the volume-return relationship of the market with a short-sale restriction, whereas the information models can explain the relationships for the markets where the costs and restriction on long and short trading are nearly or completely symmetric.

\section{References}

1. Blume, L., Easley, D.O., Hara, M. (1994). Market statistics and technical analysis: the role of volume, Journal of Finance, 49, pp. 153-181.

2. Brennan, M.J., Chordia, T., Subrahmanyam, A. (1998). Alternative factor specifications, security characteristics, and the cross-section of expected stock returns, Journal of Financial Economics, 49 (3), pp. 345-373.

3. Chordia, T., Subrahmanyam, A., Anshuman, V.R. (2001). Trading activity and expected stock returns, Journal of Financial Economics, 59 (1), pp. 3-32.

4. Chuang, C.C., Kuan, C.M. (2005). A quantile regression analysis of return-volume relation: evidence from the Taiwan and U.S. stock exchanges, Taiwan Economic Review, 33, pp. 379-404.

5. Clark, P.K. (1973). A subordinate stochastic process model with finite variance for speculative prices, Econometrica, 41, pp. 135-155.

6. Copeland, T.E. (1976). A model of asset trading under the assumption of sequential information arrival, Journal of Finance, 31, pp. 1149-1168.

7. Daigler, R.T., Wiley, M.K. (1999). The impact of trader type on the futures volatility-volume relation, The Journal of Finance, 54, pp. 2297-2316.

8. Epps, T.W. (1977). Security price changes and transaction volumes: some additional evidence, Journal of Financial and Quantitative Analysis, 12, pp. 141-146.

9. Epps, T.W., Epps, M.L. (1976). The stochastic dependence of security price changes and transaction volumes: implications for the mixture of distributions hypothesis, Econometrica, 44, pp. 305-325.

10. Hanna, M. (1978). Security price changes and transaction volumes: additional evidence, American Economic Review, 68, pp. 692-695. 
11. Harris, L. (1986). A transaction data study of weekly and intradaily patterns in stock returns, Journal of Financial and Quantitative Analysis, 16, pp. 99-117.

12. Harris, L., Gurel, E. (1986). Price and volume effects associated with changes in the S\&P 500 list: new evidence for the existence of price pressures, Journal of Finance, 41, pp. 815-829.

13. Harris, M., Raviv, A. (1993). Differences of opinion make a horse race, The Review of Financial Studies, 6, pp. 473-506.

14. He, L.Y., Yang, S., Xie, W.S., Han, Z.H. (2014). Contemporaneous and asymmetric properties in the price-volume relationships in China's agricultural futures markets, Emerging Markets Finance and Trade, 50, pp. 148-166.

15. Jenning, R., Starks, L., Fellingham, J.C. (1981). An equilibrium model of asset trading with sequential information arrival, Journal of Finance, 36, pp. 143-61.

16. Jennings, R., Barry, C. (1983). Information dissemination and portfolio choice, Journal of Financial and Quantitative Analysis, 18, pp. 1-19.

17. Karpoff, J.M. (1987). The relationship between price changes and trading volume: a survey, Journal of Financial and Quantitative Analysis, 22, pp. 109-126.

18. Karpoff, J.M. (1988). Costly short sales and the correlation of returns with volume, Journal of Financial Research, 11, pp. 173-88.

19. Kocagil, A.E., Shachmurove, Y. (1998). Return-volume dynamics in futures markets, Journal of Futures Markets, 18, pp. 399-426.

20. Koenker, R., Bassett, G. (1978). Regression quantile, Econometrica, 46, pp. 33-50.

21. McCarthy, J., Najand, M. (1993). State space modeling of price and volume dependence: evidence from currency futures, The Journal of Futures Markets, 13, pp. 335-344.

22. Moosa, I.A., Silvapulle, P., Silvapulle, M. (2003). Testing for temporal asymmetry in the price-volume relationship, Bulletin of Economic Research, 55, pp. 373-389.

23. Morgan, I.G. (1976). Stock prices and heteroskedasticity, Journal of Business, 49, pp. 496-508.

24. Puri, T.N., Philippatos, G.C. (2008). Asymmetric volume-return relation and concentrated trading in LIFFE futures, European Financial Management, 14, pp. 528-563.

25. Richardson, C., Sefcik, S.E., Thompson, R. (1986). A test of dividend irrelevance using volume reaction to a change in dividend policy, Journal of Financial Economics, 17, pp. 313-333.

26. Rogalski, R.J. (1978). The dependence of prices and volume, The Review of Economics and Statistics, 36, pp. 268-274.

27. Rogers, W.H. (1992). Quantile regression standard errors, Stata Technical Bulletin, 9, pp. 16-19.

28. Shalen, C.T. (1993). Volume, volatility, and the dispersion beliefs, Review of Financial Studies, 6, pp. $405-434$.

29. Smirlock, M., Starks, L. (1985). A further examination of stock price changes and transaction volume, Journal of Financial Research, 8, pp. 217-225.

30. Tauchen, G.E., Pitts, M. (1983). The price variability-volume relationship on speculative markets, Econometrica, 51, pp. 485-505.

31. Wood, R.A., McInish, T.H., Ord, J.K. (1985). An investigation of transaction data for NYSE stocks, The Journal of Finance, 40, pp. 723-738.

32. Ying, C. (1966). Stock market prices and volumes of sales, Econometrica, 34, pp. 676-685. 